\title{
The Political Economy of Population Ageing*
}

\author{
Georges Casamatta ${ }^{\dagger}$ and Loïc Batté
}

May 20, 2016

prepared for the Handbook of the Economics of Population Ageing

\begin{abstract}
This paper reviews the latest developments in the political economy literature that are concerned with the consequences of population ageing, with a primary focus on the threat posed by ageing to the continued existence of public pension programs in developed countries. After briefly recalling why pay-as-you-go (PAYG) public pensions are supported by a political majority in the first place, we turn to analysing how a drop in fertility or mortality rates will change the contribution rates and pension sizes at the political equilibrium, by first assuming a constant retirement age. Other theoretical works are discussed, that are mainly concerned with endogenizing the retirement age choices, and exploring the opportunity to transition to a fully-funded (FF) system. Empirical assessments of the relationship between a population age structure and the size of its pension programs are also presented.

Additionally, we explore the impact of population ageing on the political support for other public programs, such as education, heath care (including long-term care), capital taxation, or environment protection. We also give an account of some empirical analyses of the joint determination of education and pension programs.
\end{abstract}

${ }^{*}$ We would like to thank the Editor, Alan Woodland, as well as two anonymous referees, for very helpful comments.

${ }^{\dagger}$ Corresponding author. Toulouse School of Economics (GREMAQ-CNRS and CEPR); email: georges.casamatta@tse-fr.eu

${ }^{\ddagger}$ Toulouse School of Economics 


\section{Introduction}

\subsection{The political challenges of population ageing}

\subsubsection{Facts on ageing, and political consequences}

Population is ageing rapidly in all regions of the world, and even faster if one considers the most developed countries. Individuals aged 65 years or more represented $5.1 \%$ of the world population in 1950 and $8.3 \%$ in 2015 . According to recent projections (United Nations, 2015), this ratio should rise to $16.0 \%$ in 2050.

What are the reasons for this evolution? Population ageing finds its roots in two contemporaneous phenomena: a drop in mortality and fertility rates. In developed countries, the drop in fertility has mainly occurred before the 1980s and 1990s, and the fertility rate seems to have stabilized since then. In the least developed countries, however, there remains considerable room for further fertility reductions. The global total fertility rate fell from approximately 5 children per woman in 1950 to just over 2.5 in 2015 , and the UN projects that it will fall to 2.2 children per woman by 2050 (United Nations, 2015). Most of the yet-to-come decline will occur in the developing world; this will contribute to a near halving of the share of children in the population of developing countries between 1965 and 2050. The drop in mortality, or increase in longevity, is however a long-lasting trend. Average world life expectancy at birth (both sexes combined) has risen from 46.5 years in 1950 to 70.5 years in 2015. It is forecasted to continue to increase up to 77.8 years by 2050 .

The ageing of the world population introduces several major policy challenges (Bloom et al. [2010]). People aged 60 or above usually have different needs and behaviors than younger individuals. Older individuals tend to work and save less, thus negatively impacting the long-term growth potential of the economy. They also require more health care and, in many countries, rely on publicly funded pensions for a large part of their income. As older populations become larger and politically stronger, adopting certain policies (such as cutting health and pension benefits) will prove difficult, as the older generations will be more able to impose their views on political agendas, be it through their sheer weight in the electorate, or by mobilizing themselves through lobbys or interest groups (Mulligan and Sala-i Martin [1999], Hanley [2012]). Sinn and Uebelmesser [2003] even estimate that in one of the coun- 
tries most concerned by ageing, Germany, the age of the median voter will increase so quickly that it will soon become extremely hard to secure a political majority to pass pension reforms: according to them, "gerontocracy" will be a fact in Germany as soon as 2016. Individuals aged 80 or over also have different needs. With declining health the need for full-time, long-term care increases. In many cases, this also increases the need for financial support, as private savings tend to vanish rapidly for individuals with particularly long lifespans. As their numbers increase, they place further demands on government resources, familial resources, and personal savings.

\subsubsection{Policies at stake with ageing}

In this chapter, we will focus on the impact of population ageing on public programs such as social security, health care and education, that entail substantial transfers of resources between generations. It should be noted from the outset that our survey will not explore the diversity of institutional frameworks under which these programs are shaped, nor the interplay between political parties, interest groups, social movements or expert advice in defining and reforming them. We feel that the study of these important subjects is best left to political scientists (see Pierson [2007], Goldstone et al. [2011] and Vanhuysse and Goerres [2012]), and that the need to make quantitative predictions on the future evolution of these key programs requires that the political economy literature should stick to models where individual preferences aggregate into a collective vote on a limited number of features of the programs, and abstract away from the particularities of each country's and each policy's institutional features.

The main part of the chapter will be devoted to social security. Ageing has a direct and dramatic impact on the functioning of unfunded, or Pay-As-You-Go (hereafter PAYG), pension systems. In these systems, pension benefits are financed with the contributions of the workers. Population ageing implies that the proportion of recipients increases while the proportion of contributors decreases, and thus threatens the financial viability of the system. The magnitude of this phenomenon is captured by the change in the old-age dependency ratio, which is defined as the ratio of elderly (aged 65 years or more) to adult individuals (aged between 15 and 64 
years): according to the United Nations [2015], it will jump from $12.6 \%$ in 2010 to $25.6 \%$ in 2050 for the world taken as a whole, and from $26.7 \%$ to $45.8 \%$ for developed economies $^{1}$ over the same time frame. Meier and Werding [2010] give an order of magnitude of the increased burden that would represent if the system (and notably the replacement rate $)^{2}$ was left unchanged: for a subset of OECD economies, the increase in pension spending to GDP would spread from $3 \%$ (for the UK) to $21 \%$ for Poland, over the 2000-2050 period. In many cases, this pension-spending-to-GDP ratio would be more than doubled over the period, should no reform be enacted.

Together with these changes in the age composition of the population, most OECD countries have also experienced a large drop in the labor force participation of middle-aged and elderly workers, which contributes to aggravating the financial difficulties of pension systems. As we will see later in this chapter, this drop is mainly due to the design of social security systems, which induces people to retire early, as well as other programs of the welfare state (amongst which unemployment benefits and disability insurance).

Confronted to this demographic evolution, pension systems thus need to be reformed. A substantial part of this chapter will be devoted to the political sustainability of such reforms. In a democratic society, this amounts to identifying the reforms which are likely to receive the support of a majority of the voters. Two kind of reforms of PAYG systems can be envisioned. The first one consists in keeping the system unchanged, but simply adjust its parameters, that is the contribution rate, the pension benefit level or the retirement age. This is called a parametric reform. The other possibility consists in changing the system and move to a fully funded (hereafter FF) or a notional defined-contribution (NDC, see below) system: this is called a structural reform.

An analysis of the political sustainability of social security under ageing needs to examine the individuals' position on social security. Preferences over social security typically depend on an individual's age - since different cohorts of people have different remaining periods of contributions and benefits, but also on the redistributive

\footnotetext{
${ }^{1}$ As defined in the report cited above: Europe, Northern America, Australia, New-Zealand and Japan.

${ }^{2}$ The replacement rate of a pension system is defined as the average ratio of individual pensions to wages before retirement.
} 
design of the system. To assess the political sustainability of social security, one has to aggregate these preferences into a collective choice procedure. In this chapter, we focus almost exclusively on majority voting.

Once we have determined how these individual preferences shape the collective choice that arises out of majority voting, we can study how population ageing affects this democratic choice. Demographic dynamics impact the majority voting equilibrium over social security in essentially two ways. It modifies individuals' preferences - through for example the change in the rate of return of the pension system or equilibrium prices. But it also changes the identity of the decisive voter: when population ages, the median voter becomes older and therefore individuals at or close to retirement get more political power.

\subsection{Features of social security systems and recent reforms}

Most industrialized countries feature an unfunded social security system that collects contributions from the workers' labor income and uses the revenue raised to provide pension benefits to current retirees. The first unfunded public program of retirement income was introduced in Germany in the late nineteenth century; several other countries followed at the beginning of the twentieth century - often with the creation of small funded systems targeted to workers in specific sectors. By the end of World War II, most systems had become unfunded. Until the beginning of the nineties, these systems have constantly grown, either because of the extension of coverage among workers, or due to an increase in the generosity of pension benefits. Since then, governments, recognizing the long-term financial effect of the ageing process, have started to adopt retrenching measures.

\subsubsection{Features of social security systems}

Social security systems are designed to provide replacement income for old age under a variety of circumstances and, as such, need to combine different mechanisms called pillars or tiers, ${ }^{3}$ that each functions in a specific way and provides for different needs. For ease of exposition, we will retain here only two main roles played by the pension

\footnotetext{
${ }^{3}$ The pillar denomination seems to originate from the World Bank, see for instance World Bank [2008]; while the classification in tiers emanates from the OECD, see for instance OECD [2015].
} 
systems. The first role or tier typically refers to non-contributory provision of basic income for persons older than a certain threshold, with a clear aim at alleviating old-age poverty. It is usually financed out of general taxation. The second tier, in constrast, provides an amount of income that is linked to past contributions made to the system, and has an insurance (rather than a redistributive) objective.

This second tier of the social security system of a given country ${ }^{4}$ can be classified into four broad categories, as a combination of two key features: (a) pension systems are either fully funded or unfunded (henceforth referred to as pay-as-you-go or PAYG), (b) a system can provide payments based on either defined benefits or defined contributions. A system is deemed "defined benefits" (henceforth DB) if the benefits accrued at retirement are predetermined based on a formula that takes into account mainly life earnings, years of contribution and age, while a "defined contribution" system does not guarantee future pension levels, which are calculated by applying a (market-based or fictitious) rate of return on contributions. Additionally, it should be noted that some countries feature both a funded and an unfunded component in their pension system, making any attempt at a general typology of pension system rather obscure. ${ }^{5}$

Funded defined-contribution system Chile's social security reform in 1981 remains the best known international example of a FF defined contribution system. Under the Chilean system, all workers are required to contribute 10 percent of their salary into a savings plan of their choice, which is administered and regulated by the Administradora de Fondos de Pensiones. Eligibility for retirement is based on age and early retirement is available to those with sufficient accumulated savings. At retirement, workers can choose monthly withdrawals or purchase an annuity. Furthermore, workers are guaranteed a minimum pension paid from the general revenue fund. The benefits of such a system include reduced exposure to political and demographic risks.

Several other countries, including most of Latin America, have a funded defined-

\footnotetext{
${ }^{4}$ We henceforth only refer to this second tier of the pension system of a given country as "the system" for brevity.

${ }^{5}$ The interested reader will find in subsection 1.2.2 some useful references that describe the pension systems of given countries using a coherent typology.
} 
contribution pillar that follows Chile's example. Valdés-Prieto [1999] presents, among other things, a summary of the reforms that took place in seven Latin American countries, following Chile's example. He offers five reasons why Chile's model is so successful, including low levels of private-sector corruption, little political pressure on investment options, and successful implementation of a redistributive means-tested benefit to workers not covered by the Administradora de Fondos de Pensiones.

In Australia also the system is funded with defined contributions. The peculiarity of this system is that it offers the choice of either a lump-sum payment or an annuity at retirement. The U.K. system also offers a privatized, funded definedcontribution system but a unique one, in that it allows workers to opt out of their public, unfunded, defined-benefit system.

Funded defined-benefit system More traditional pensions, similar to those awarded to older U.S. workers during previous decades, are good examples of funded defined-benefit systems. Workers pay into the pension system, and the corporation manages how these contributions are invested. Workers then receive a defined benefit at retirement, which is usually based on years of service or some other related measure. Switzerland currently offers a hybrid system: a funded defined-contribution system with a guaranteed minimum return.

Unfunded defined-benefit system A publicly operated, unfunded defined-benefit plan constitutes the main system of social security among a majority of OECD countries, including for instance France and Spain. Pension benefits may be granted to every individual that complies with the age and contribution range requirements, or may be means-tested (such that only workers below an income threshold are eligible).

Unfunded defined-contribution system Sweden and Italy are concrete examples of countries with an unfunded defined-contribution social security system. In recent years, both countries have switched to a so-called NDC ("notional defined contribution") plan. The government credits each worker for the taxes he or she and the employer contribute, and then pays upon retirement a benefit equal to the 
worker's contributions plus a notional (i.e. not market-based) interest rate.

Pension benefits and eligibility Benefits are computed based on the number of years of contributions and on a reference wage, which typically depends on the worker's past wages. However, even countries with a defined-benefit system differ in how pensions relate to the reference wage and in how this reference wage is obtained. France, Germany and Spain feature a tight link between wages and benefits. In these so-called Bismarckian systems, the benefit formula is constructed so as to entitle the retirees to a pension income that replaces a certain share (called the replacement rate) of their previous labor income. On the contrary, the United Kingdom exhibits an essentially redistributive system (often referred to as Beveridgian). The basic state pension is not related to any reference wage, and depends mostly on the number of years of contributions only.

Benefits are most of the time indexed on inflation or to the net wage growth, to reflect the increase in the cost of living. Eligibility to these benefits may depend on the years of contributions and/or on a minimum retirement age.

Retirement age All countries feature an official retirement age, when people are allowed, if not forced, to exit the labor market and receive their pension benefits. Most countries also have early retirement provisions that allow workers to retire before the official age on a reduced pension benefit. On top of that, some countries (like France) allow workers to enjoy full pensions even if they did not contribute to the system during the required amount of years, provided they have reached an age that is slightly higher than the official retirement age.

\subsubsection{Recent reforms}

It is outside the scope of this chapter to provide a detailed account of the state of pension program reforms ${ }^{6}$ in any economy taken individually, as every country exhibits specific provisions linked to the history of its public pension system development, the national public debate on the subject, and other idiosyncrasies such as how much the recent crisis hit public finances. We refer the reader interested by

\footnotetext{
${ }^{6}$ To get an overview of recent reform trends, see Holzmann [2012].
} 
very up-to-date information on any particular country to periodic reports made by international or specialized institutions to cover the specifics of recent reforms on all aspects of pension programs. Notably, the "Social Security Programs Throughout the World" reports, issued by the American Social Security Administration jointly with the International Social Security Association, give detailed accounts of most features of the pension system of every country in a given area of the world, every six months on a rotating basis for the different regions (see e.g. the latest report for the Americas: U.S. Social Security Administration [2016]).

Other international organizations are also publishing reports on the situation of pension programs in their member states for policy coordination purposes: see for instance OECD [2014], OECD [2015] for OECD countries, or European Commission [2010] for the EU. OECD [2015], for instance, examines pension reforms in its member countries between 2013 and 2015, noticing a trend towards less favourable indexation mechanisms, rather than direct cuts in pensions, and increased incentives to work longer in many member states. Another feature common to OECD member states is, according to the report, renewed effort to provide social assistance to the old poor in the form of minimum, non-contributory pensions, or increased levels of pensions for people having worked short careers. Additionally, past trends aimed at financial sustainability are still present: minimum retirement age keeps being more and more tied to life expectancy, and benefits levels are increasingly tied to the whole contribution history rather than the last years (or best years in terms of wage) of an individual's career. European Commission [2010] also adds that eligibility criteria now more and more include a statutory number of contribution years on top of the minimum age. Recent reforms are also shown to be aimed at lengthening working lives, either through increases in statutory retirement age, provision of financial incentives to work while in retirement, or the retrenchment of generous early retirement schemes. These reforms are sometimes coupled with labor market reforms aimed at promoting employment of older workers from the labor demand side, with incentives given to firms that hire workers close to retirement. Finally, furthering diversification and security of the pension plans available to workers has been brought through the establishment of voluntary pension plans and increase 
in competition between private providers, or by relaxing restrictive regulations over investment choices made by the individuals (when saving to a private fund) and pension funds (to increase diversification of their portfolios). In this respect, European Commission [2010] notes an "increased complexity of pension systems [meaning] a transfer of risk from pension scheme sponsors to the beneficiaries".

Additionally, European Commission [2010] notices a trend towards the prefunding of future pension outlays, which consists in frontloading parts of the adjustments costs linked to ageing in order to distribute them over a longer period and over several generations. This pre-funding typically is made by establishing a pension reserve fund, paying down national public debt, ${ }^{7}$ or reforming the systems from defined benefits to defined contributions.

\subsection{Contribution of this chapter and outline}

\subsubsection{Contribution of this survey}

This chapter naturally builds on previous surveys of the literature on the political economy of intergenerational transfers, notably Breyer [1994b], Galasso and Profeta [2002] or de Walque [2005]. ${ }^{8}$ Among other things, Breyer [1994b] provides a clear classification of the assumptions made by the various theoretical models that deal with our topic: the time structure of the model, the validity of the decision (onceand-for-all voting or not), the decision rule or the characteristics of voters in the same cohort are some of the assumptions that are discussed. He also compares the political decisions regarding the pension system to the decision to accumulate some government debt, an issue rarely tackled elsewhere.

Galasso and Profeta [2002] review works that aim to study the interactions between social security systems and other redistributive programs of the welfare state. They also briefly analyse the first multidimensional voting models involving social security, that were used to understand the joint determination of several features of social security systems. Another notable contribution is their review of the early

\footnotetext{
${ }^{7}$ Once we take into account the fact that the state is financing the deficits of universal unfunded systems in many countries, it becomes clear that social security deficits add up each year to the implicit public debt, so that reducing public debt now in order to run social security deficits in the future is as effective as building up a pension reserve fund.

${ }^{8} \mathrm{~A}$ more recent survey on some aspects of this literature can be found in Pamp [2015].
} 
literature on the political sustainability of social security following a demographic shock, as well as on the feasibility of reforms.

This survey expands on those cited above, first by giving an account of more recent work that aims at explaining the emergence of social security: for instance, one issue that has received increased attention in the last decade is the existence of within-cohort heterogeneity, especially concerning life expectancy at retirement. Heterogeneity within the cohort of current workers may help explain why there is a political majority that supports the existence of a (partly redistributive) pension system in equilibrium. We also review recent work on the political determination of the retirement age, whether as a stand-alone policy dimension or in conjunction with the size of pensions. Besides, we give an account of theoretical models in which the once-and-for-all-voting assumption is relaxed, this assumption being a clear limitation of the early literature on the political economy of pensions.

In this chapter, we also report on the recent empirical analyses and simulations of the effect of ageing on the political determination of the size of pension programs. In particular, we show that the choice of the variables used in empirical studies to represent the changing age structure of population have a tremendous impact on the conclusions drawn by these studies. Additionally, the use of simulations allows to make quantitative predictions on the future evolution of the retirement age, contribution and replacement rates in a selection of major OECD countries, of which we give a brief summary.

Finally, we believe this chapter contributes to the understanding of how population ageing impacts other public programs beyond (or in conjunction with) social security. We give an account of the complementarity at the political decision-making level between public funding of education and pensions, a mechanism that was first recognised as important from a normative point of view a decade ago: the recent political economy literature envisions the possibility that voters may take into account such a relationship between the two policies when stating their policy preferences. 


\subsubsection{Outline}

In a first step, we consider that the retirement age is fixed, so that a PAYG pension system is characterized by its contribution rate and its level of benefits, and examine in section 2 the reasons why a majority of the population may sustain a PAYG pension system. These reasons are the following. First of all, the economy may be dynamically inefficient. This implies that the rate of population growth exceeds the interest rate. In other words, the rate of return of the PAYG system is larger than the rate of return of a FF system. ${ }^{9}$ It follows that individuals find the PAYG system to be a better "investment" opportunity than the FF system. Browning [1975], in his seminal paper, noted that the economy need not be dynamically inefficient for a majority of the population to support the PAYG system. His argument relies on the idea that past contributions to the social security system are a sunk cost for individuals. These latter, in evaluating the relative return of a PAYG and a FF system, compare the contributions that remain to be paid to the future pension benefits they expect to receive. It is then clear that an individual close to retirement receives a very high return from the PAYG system. If the median voter (who is the median age individual) is close enough to retirement, he will therefore vote for a PAYG system.

Previous arguments were developed in a partial equilibrium setting. In a general equilibrium, the introduction of a PAYG system depresses savings and thus makes the interest rate increase. This provides an additional reason for the voters to support PAYG. Besides, pension systems not only redistribute wealth across generations, they also redistribute within cohorts. As a consequence, a sufficiently redistributive PAYG system may be sustained by a coalition of the retirees and the poor workers. Finally, a PAYG system may constitute a device to insure individuals against the fluctuations of the interest rate.

We then turn in section 3 to the political determination of the retirement age. Two different frameworks are considered. In the first one, individuals freely decide when to retire. They however vote on some features of the PAYG system that affect their retirement decision. In the second framework, we consider that the majority

\footnotetext{
${ }^{9}$ We assume for simplicity that there is no wage growth.
} 
vote applies to the retirement age, which is unique and common to all individuals.

The previous arguments were made under the once-and-for-all voting assumption: when voting on the contribution rate, individuals anticipate that the chosen tax rate will apply to their retirement period. A strand of the literature has shown that this assumption can be rationalized as the equilibrium outcome of an infinitely repeated game. In each period, the young voters sustain the system because of the fear to be punished by the subsequent generations. This game, which allows to explain the social contract between generations, is analyzed in sections 4.1 and 4.2 . Its main drawback is that it has many (subgame perfect) Nash equilibria. Section 4.3 develops a recent literature on social security as a Markov perfect equilibrium, which is a refinement of the Nash equilibrium. The payroll tax rate is assumed to be a function of some state variables, for example the capital stock. This creates a link between generations: if some generation decides to alter the tax rate in a given period, it will impact the capital stock in the next period and, through the Markov link, the tax rate in this next period.

A widely discussed reform of the social security system consists in moving from a PAYG to a FF system. This latter having a larger rate of return, many observers propose to change the system. Some authors have however shown that this transition cannot be Pareto improving, as it only results in making the implicit debt of the PAYG system explicit. Only when the PAYG system generates some distortions could the transition to a FF system be Pareto improving. We discuss this reform in section 5 .

Section 6 presents quantitative, rather than theoretical, analysis of the consequences of population ageing, by first reporting empirical evidence and then turning to simulation work. Section 7 deals with other public programs that are likely to be affected by population ageing, mainly health care and education. Lastly, section 8 concludes. 


\section{Why individuals support PAYG social security}

\subsection{Dynamic inefficiency}

We present the basic two-period overlapping generations (hereafter OLG) model that is used for analyzing pension policy. We consider a small open economy, so that the wages and the interest rate are given. Individuals live two periods. In any given period, two generations thus coexist: the young $y$ and the old $o$. The size of each cohort at time $t$ is denoted $N_{t}^{y}$ and $N_{t}^{o}$ respectively. Let assume that population grows at a constant rate $n$, so that $N_{t}^{y}=(1+n) N_{t}^{o}$. Lifetime utility of the generation born in $t$ depends on consumptions in young and old ages and is assumed to be additively separable: $U\left(c_{t}^{y}, c_{t+1}^{o}\right)=u\left(c_{t}^{y}\right)+\beta u\left(c_{t+1}^{o}\right)$, where $\beta$ is the discount factor. Assuming each individual earns the same income, normalized to 1 , when young, ${ }^{10}$ he chooses savings $s_{t}$ in order to solve:

$$
\begin{array}{cc}
\max _{s_{t}} & U\left(c_{t}^{y}, c_{t+1}^{o}\right) \\
s t & \\
& c_{t}^{y}=1-s_{t} \\
& c_{t+1}^{o}=s_{t}\left(1+r_{t+1}\right)
\end{array}
$$

where $r_{t}$ is the interest rate. This leads to the first-order condition on savings:

$$
u^{\prime}\left(c_{t}^{y}\right)=\beta\left(1+r_{t+1}\right) u^{\prime}\left(c_{t+1}^{o}\right)
$$

Consider now the introduction of a PAYG social security system. Each individual contributes a fraction $\tau$ of his income when young and receives a pension benefit $p$ when old. The budget constraint of the system in each period is:

$$
\begin{gathered}
\tau N_{t}^{y}=p N_{t}^{o} \\
\Leftrightarrow \quad p=\tau(1+n) .
\end{gathered}
$$

With the PAYG system, consumptions in both periods are $c_{t}^{y}=1-\tau-s_{t}$ and $c_{t+1}^{o}=s_{t}\left(1+r_{t+1}\right)+\tau(1+n)$. The effect of introducing a PAYG system at any time $t_{0}$ on the welfare of generations born after $t_{0}$ is given by:

\footnotetext{
${ }^{10}$ Wage growth is thus ruled out by assumption. This is for expositional simplicity, results continue to hold with this assumption relaxed.
} 


$$
\left.\frac{\partial V}{\partial \tau}\right|_{\tau=0}=-u^{\prime}\left(c_{t}^{y}\right)+\beta(1+n) u^{\prime}\left(c_{t+1}^{o}\right),
$$

where $V$ is the indirect utility function. From (1), we see that this expression is positive when $n>r_{t}$, a condition known as dynamic inefficiency. Noting that the introduction of the PAYG system constitutes a windfall for the old of the initial period, it is found that the PAYG system is Pareto improving when the economy is dynamically inefficient (Samuelson [1958], Aaron [1966]). Whether the economy is dynamically efficient or not is a debated issue (Abel et al. [1989], Homburg [1991], Geerolf [2013]). However there exist other reasons, that we examine in the next sections, why individuals support social security even when the economy is dynamically efficient.

\section{$2.2 \quad$ Reduced time horizon}

\subsubsection{Central argument}

Browning [1975] provided the first analysis of a majority vote over pensions. He considers a small open economy (in which the interest rate is given) with individuals differentiated according to age only (in particular there is no income heterogeneity). They live three periods, meaning that three generations coexist in each period, the young $y$, the middle-aged $m$ and the old $o$. Under this setup, preferences are singlepeaked over the payroll tax rate, implying that a Condorcet winner exists (Black [1948]). ${ }^{11}$ This policy is the majority-voting equilibrium of a standard two-party Downsian electoral competition game (Roemer [2001]).

With three generations, noting that $N_{t}^{o}=(1+n)^{2} N_{t}^{y}$ and $N_{t}^{m}=(1+n) N_{t}^{y}$, the budget constraint of the PAYG system writes:

$$
\begin{aligned}
& N_{t}^{o} p_{t}=N_{t}^{y} \tau_{t}+N_{t}^{m} \tau_{t} \\
\Leftrightarrow & p_{t}=\tau_{t}(1+n)(2+n) .
\end{aligned}
$$

It is assumed that there are no future re-voting opportunities. In other words, individuals vote with the belief that the contribution rate chosen today will not be

\footnotetext{
${ }^{11}$ The Condorcet winner is the tax rate that is preferred by more than one half of the population, when confronted to any other possible tax rate.
} 
modified in the future $\left(\tau_{t+1}=\tau_{t} \equiv \tau\right)$. Under this assumption, the optimal payroll tax rate of the decisive voter (who is a median-aged individual) solves:

$$
\begin{array}{cc}
\max _{\tau} & V_{t}^{m}(\tau) \equiv u\left(c_{t}^{m}\right)+\beta u\left(c_{t+1}^{o}\right) \\
\text { st } & \\
& c_{t}^{m}=1+s_{t}^{y}(1+r)-s_{t}^{m}-\tau \\
& c_{t}^{o}=s_{t}^{m}(1+r)+\tau(1+n)(2+n) .
\end{array}
$$

He chooses a positive payroll tax rate if $\partial V_{t}^{m} /\left.\partial \tau\right|_{\tau=0}>0$. Using the optimality condition on private savings, $(1)$, this will be the case when $(1+n)(2+n)>1+r$. In words, this implies that he may sustain the PAYG system even when the economy is dynamically efficient. The reason for this is that past contributions to the system are sunk cost. At the time of the vote, he compares the benefit of the system, $\tau(1+n)(2+n)$, to its cost, $\tau$. The rate of return of the system is thus $(1+n)(2+n)$, which is larger than the rate of return of the young, $1+n .{ }^{12}$ More generally, the closer individuals are to retirement, the higher the rate of return of the system. As a consequence, optimal tax rates are increasing with age. Noting that the steady state socially optimal tax rate is the one maximizing life cycle utility at birth, Browning reaches the conclusion that the voted tax rate, that corresponds to the preferences of the middle-aged, is too high. In other words, voting leads to a pension system excessively generous.

In this stylized economy, middle-aged individuals vote for a $100 \%$ tax rate. They prefer to "invest" all their income in the social security system and finance current consumption by borrowing. There exist however obvious limits to the size of the system. First of all, when borrowing is constrained, agents need to keep resources for consumption in the working period (Boadway and Wildasin [1989]). The presence of uncertainty about future voting outcomes may also dissuade them to adopt too high tax rates (Hu [1982]). Finally, distortions caused by taxation are absent from Browning's analysis. With distortionary taxation, the voted tax rate lies strictly between 0 and 1 (Breyer [1994a]).

\footnotetext{
${ }^{12}$ These latter vote for a zero tax rate in a dynamically efficient economy.
} 


\subsubsection{Population ageing in the Browning model}

We consider the impact of population ageing in the framework just described. In this purpose we formulate a simple continuous version of this model. Assuming no time discounting and no savings for simplicity, the life cycle utility of an aged $a$ worker writes:

$$
\int_{a}^{R} u(1-\tau) d t+\int_{R}^{T} u(p) d t=(R-a) u(1-\tau)+(T-R) u(p),
$$

where $R$ is the age of retirement and $T$ the length of life.

The budget constraint of the PAYG system is:

$$
p=\frac{F(R)}{1-F(R)} \tau,
$$

where $F($.$) is the c.d.f. of the age distribution and we denote N^{y}=F(R)$ the number of workers (recall that the retirement age is assumed to be fixed). The optimal contribution rate of an aged $a$ worker solves the following first-order condition:

$$
-(R-a) u^{\prime}\left(c^{y}\right)+(T-R) \frac{N^{y}}{1-N^{y}} u^{\prime}\left(c^{o}\right)=0,
$$

where $c^{y}=1-\tau$ and $c^{o}=p$.

Obviously, and for the reason explained in the previous section, $\partial \tau^{y} / \partial a>0$, so that the majority voting tax rate is the preferred tax rate of the individuals with median age $a^{m}$.

Now consider a change in the fertility rate that makes the ratio $\eta \equiv N^{y} /\left(1-N^{y}\right)$ decrease. As a consequence the median age increases and the total effect on the majority voting tax rate is: ${ }^{13}$

$$
\frac{d \tau^{*}}{d \eta}=\frac{\partial \tau^{y}}{\partial \eta}+\frac{\partial \tau^{y}}{\partial a^{m}} \frac{d a^{m}}{d \eta}
$$

As explained before, the second term is negative. The first term is obtained by differentiating (3):

$$
\frac{\partial \tau^{y}}{\partial \eta}=\frac{(T-R) u^{\prime}\left(c^{o}\right)(1-\varepsilon)}{-D_{\tau}}
$$

\footnotetext{
${ }^{13}$ We are interested here in the comparison of steady states and do not address the question of the demographic transition.
} 
where $\varepsilon=-x u^{\prime \prime}(x) / u^{\prime}(x)$ is the coefficient of relative risk aversion and $D_{\tau}<0$ is the derivative of the first-order condition (3) with respect to $\tau$. One can show that $\varepsilon$ is equal to the inverse of the intertemporal elasticity of substitution.

Individually optimal tax rates increase with $\eta$ when $\varepsilon<1$. When $\eta$ decreases, the rate of return of the PAYG system becomes lower. In other words, the price of second-period relatively to first-period consumption increases and individuals are induced to substitute first- for second-period consumption. This is achieved by decreasing the tax rate. But the income effect goes into the opposite direction. With a high enough intertemporal elasticity of substitution, the substitution effect dominates so that individuals react to a drop in the fertility rate by increasing the tax rate.

In this case, we see that the total effect of an increase in the dependency ratio (equal to $1 / \eta$ ) on the equilibrium tax rate is ambiguous. The direct, economic effect calls for a reduction in the size of the system. But at the same time, in a greying society the increased political power of the old pushes toward a higher tax rate.

What is the consequence of an increase in life expectancy? This change leads to a reduction in $\eta$ and therefore have similar effects as previously. There is however an additional economic effect. Because individuals live longer and thus spend more time on retirement (for a given retirement age), they should invest more resources in PAYG to ensure a decent standard of living at retirement:

$$
\frac{\partial \tau^{y}}{\partial T}=\frac{\eta u^{\prime}\left(c^{o}\right)}{-D_{\tau}}>0
$$

\subsection{Effect of social security on prices}

Diamond [1965] extended the analysis of Samuelson [1958] to a model with production. In this context, the introduction of PAYG social security crowds out private savings and thus lowers the capital stock. This in turn implies lower wages and a higher interest rate. It follows that social security may, through its positive effect on the interest rate, be sustained by a majority of voters in a dynamically efficient economy (Cooley and Soares [1999], Boldrin and Rustichini [2000]).

Consider the extension of the simple model in subsection 2.1 to a closed economy with wage in period $t$ denoted $w_{t}$. The program of the representative young agent 
in period $t$ remains the same with consumptions in both periods equal to $c_{t}^{y}=$ $w_{t}(1-\tau)-s_{t}$ and $c_{t+1}^{o}=s_{t}\left(1+r_{t+1}\right)+\tau w_{t+1}(1+n)$. Denoting $f$ the production function from per capita capital $k$, the equilibrium conditions on the production side are

$$
\begin{aligned}
w_{t} & =w\left(k_{t}\right)=f\left(k_{t}\right)-k_{t} f^{\prime}\left(k_{t}\right) \\
1+r_{t} & =r\left(k_{t}\right)=f^{\prime}\left(k_{t}\right) \\
k_{t+1} & =s_{t} /(1+n) .
\end{aligned}
$$

The effect of the introduction of a PAYG system is now given by:

$$
\left.\frac{\partial V}{\partial \tau}\right|_{\tau=0}=-w_{t} u^{\prime}\left(c_{t}^{y}\right)+\beta\left(\left(w_{t+1}+\frac{\partial w_{t+1}}{\partial k_{t+1}} \frac{\partial k_{t+1}}{\partial \tau}\right)(1+n)+\frac{\partial r_{t+1}}{\partial k_{t+1}} \frac{\partial k_{t+1}}{\partial \tau} s_{t}\right) u^{\prime}\left(c_{t+1}^{o}\right) .
$$

There are two new terms with respect to (2). The introduction of the PAYG system depresses savings: $\partial k_{t+1} / \partial \tau<0$. With less capital, the wage rate in period $t+1$ decreases (first term negative), but at the same time the interest rate increases (second term positive). If this second effect dominates, introducing a PAYG system has a positive effect on prices from a welfare perspective.

\subsection{Within cohort redistribution}

Even in a dynamically efficient economy, poor young individuals may support the PAYG system because of its (intragenerational) redistributive properties (Meltzer and Richard [1981], Tabellini [2000], Casamatta et al. [2000]). We consider a twoperiod OLG model of a small open economy. There is wage heterogeneity within cohorts: $w \in[w-, w+]$, with the average wage larger than the median $\left(\bar{w}>w_{m}\right)$ and agents are assumed to be credit constrained. ${ }^{14}$ The pension formula is

$$
p(w)=(1+n) \tau(\alpha w+(1-\alpha) \bar{w})
$$

where $\alpha \in[0,1]$ is a parameter that represents the link between contributions and benefits. It is a measure of the redistributiveness of the pension system. A low value of $\alpha$ implies a highly redistributive, or Beveridgian, pension system (for $\alpha=0$, everyone receives the same pension, whatever the level of contributions). Large values of $\alpha$ correspond to a contributory, or Bismarckian, system.

\footnotetext{
${ }^{14}$ In order to have interior optimal tax rates. See discussion at the end of section 2.1.
} 
The analysis is conducted at steady state under the once-and-for-all voting assumption.

\subsubsection{Individually optimal tax rates}

We first determine the tax rates that maximize the life cycle utility of the different agents, considering first the retirees and then the workers.

The retirees Private saving is the result of past decision. The retirees choose the value of $\tau, \tau^{o}$, that maximizes their consumption: $c^{o}=(1+r) s+(1+n) \tau(\alpha w+$ $(1-\alpha) \bar{w})$. The solution is straightforward: $\tau^{o}=1$, the same tax rate for all retirees.

The workers A worker with earning $w$ chooses $\tau^{y}(w)$ in order to maximize

$$
V(\tau, w)=u\left(w(1-\tau)-s^{y}\right)+\beta u\left((1+r) s^{y}+(1+n) \tau(\alpha w+(1-\alpha) \bar{w})\right)
$$

where $s^{y} \geq 0$ is the optimal level of private saving.

If $1+r>($ resp. $<)(\alpha+(1-\alpha) \bar{w} / w)(1+n)$, the individual optimal policy involves $\tau^{y}=0($ resp. $>0)$ and $s^{y}>0$ (resp. $\left.=0\right)$. Put differently, for an individual to prefer private saving to PAYG pensions, his wage must be strictly higher than $\hat{w}$ defined as:

$$
\hat{w}=\frac{1-\alpha}{\frac{1+r}{1+n}-\alpha} \bar{w} \leq \bar{w} .
$$

One easily checks that $\hat{w}=\bar{w}$ if $n=r, \partial \hat{w} / \partial n>0$ and $\partial \hat{w} / \partial \alpha<0$. Indeed, a larger $n$ means a higher return of the PAYG system. It thus explains why more workers support the system $(\partial \hat{w} / \partial n>0)$. Moreover a less redistributive system ( $\alpha$ increases) receives less political support $(\partial \hat{w} / \partial \alpha<0)$. One can also check that the indirect utility function $V($.$) is concave in \tau$, meaning that preferences are single-peaked and therefore that the median voter theorem applies.

\subsubsection{Variation of the optimal tax rates with the wage level}

Let us now take a look at how the optimal tax rate changes with the individual wage $w \leq \hat{w}$. Differentiating the first-order condition on $\tau^{y}$,

$$
-w u^{\prime}\left(c^{y}\right)+\beta(1+n)(\alpha w+(1-\alpha) \bar{w}) u^{\prime}\left(c^{o}\right)=0,
$$


we obtain

$$
\frac{\partial \tau^{y}}{\partial w}=\frac{\beta(1+n)(1-\alpha) \frac{\bar{w}}{w} u^{\prime}\left(c^{o}\right)(1-\varepsilon)}{V^{\prime \prime}(\tau)}
$$

where $\varepsilon$ is the coefficient of relative risk aversion. Optimal tax rates increase with wages if and only if $\varepsilon>1$. A variation of the wage level generates an income and a substitution effect. When the wage increases:

1) The individual is richer. Because consumption in the second period is a normal good, he wants to increase it. This is achieved by increasing the tax rate (income effect).

2) The price of first-period consumption with respect to second-period consumption, $(1+n)(\alpha w+(1-\alpha) \bar{w}) / w$, decreases. By this effect, richer individuals are induced to buy more first period consumption and this is achieved by reducing the tax rate (substitution effect).

When the intertemporal elasticity of substitution is small $(\varepsilon>1)$, the income effect dominates: individually optimal tax rates are increasing with wages.

\subsubsection{Majority voting tax rate}

The workers are divided into two classes, those who prefer a zero tax rate and positive savings and those who prefer a positive tax rate and no saving. A fraction $1 /(2+n)$ of citizens, the retirees, is in favor of $\tau^{R}=1$. Furthermore, all workers with earnings above $\hat{w}$ are in favor of a zero tax and the preferred tax rate of the workers with earnings below $\hat{w}$ increases (resp. decreases) with $w$ if $\varepsilon>1$ (resp. $<1)$. For the majority voting tax rate to be positive, it must be that the number of individuals who want a positive rate is larger than half the total population:

$$
\begin{aligned}
N_{t}^{y} \int_{w_{-}}^{\hat{w}} f(w) d w+N_{t}^{o} & \geq \frac{N_{t}^{y}+N_{t}^{o}}{2} \\
\Leftrightarrow \quad \int_{w_{-}}^{\hat{w}} f(w) d w & \geq \frac{n}{2(1+n)} .
\end{aligned}
$$

Under this condition, ${ }^{15}$ the majority voting equilibrium tax rate is the rate preferred by the workers with earning $\tilde{w}$, such that the number of people who prefer a higher tax rate is exactly half the total population. For $\varepsilon>1$ (increasing tax rates), it

\footnotetext{
${ }^{15}$ Note that this condition is always satisfied when $n \geq r$. It could however be violated in the converse case.
} 
solves:

$$
\begin{aligned}
N_{t}^{y} \int_{\tilde{w}}^{\hat{w}} f(w) d w+N_{t}^{o} & =\frac{N_{t}^{y}+N_{t}^{o}}{2} \\
\Leftrightarrow \quad \int_{\tilde{w}}^{\hat{w}} f(w) d w & =\frac{n}{2(1+n)} .
\end{aligned}
$$

This corresponds to an ends-against-the-middle equilibrium (Epple and Romano [1996]): a coalition of the middle-class and the retirees support a larger PAYG system whereas the poor and rich workers would like to downsize it.

For $\varepsilon<1$ (decreasing tax rates), $\tilde{w}$ is implicitly defined by:

$$
\int_{w_{-}}^{\tilde{w}} f(w) d w=\frac{n}{2(1+n)} .
$$

It corresponds to the situation in which the PAYG system is supported by a coalition of the retirees and the poor workers.

\subsubsection{Effect of a drop in the fertility rate}

A change in the fertility rate has both a direct and an indirect effects on the majority voting tax rate. The direct effect is obtained by differentiating the first-order condition (4):

$$
\frac{\partial \tau^{y}}{\partial n}=\frac{\beta(\alpha w+(1-\alpha) \bar{w}) u^{\prime}\left(c^{o}\right)(1-\varepsilon)}{-V^{\prime \prime}(\tau)} .
$$

Optimal tax rates increase with $n$ if and only if $\varepsilon<1$. When $n$ decreases, the rate of return of the PAYG system becomes lower. In other words, the price of secondperiod relative to first-period consumption being larger, individuals are induced to substitute first for second period consumption. This is achieved by decreasing the tax rate. But the income effect goes into the opposite direction. With a large enough intertemporal elasticity of substitution, the substitution effect dominates so that individuals react to a drop in the fertility rate by decreasing the tax rate.

Following a change in the fertility rate, not only optimal tax rates are modified but also the identity of the decisive voter. When the intertemporal elasticity is low, $\tilde{w}$ is given by (5). Differentiating this condition, we obtain:

$$
\frac{d \tilde{w}}{d n} f(\tilde{w})=\frac{1}{2(1+n)^{2}}-\frac{d \hat{w}}{d n} f(\hat{w})
$$

Noting that $\partial \hat{w} / \partial n>0$, this effect has an ambiguous sign. 
In the case of a high intertemporal elasticity, we differentiate (6) to obtain:

$$
\frac{d \tilde{w}}{d n} f(\tilde{w})=\frac{1}{2(1+n)^{2}}>0 .
$$

The total effect on the majority voting tax rate is given by:

$$
\frac{d \tau^{*}}{d n}=\frac{\partial \tau^{y}}{\partial n}+\frac{\partial \tau^{y}}{\partial w} \frac{d \tilde{w}}{d n} .
$$

When $\varepsilon>1$ the direct effect is negative and the indirect one ambiguous. When $\varepsilon<1$ the direct effect is positive and the indirect effect negative. Therefore, one cannot conclude unambiguously about the effect of a drop in fertility. The direct and indirect effects go in opposite directions and one needs to evaluate the magnitude of these countervailing effects to be able to conclude about the global direction of the change.

\subsubsection{Myopic individuals}

Cremer et al. [2007] develop a political economy analysis that describe the majority vote over PAYG pensions when some individuals are myopic, in the sense that they do not discount the future "correctly" ${ }^{16}$ They consider a model which is basically the same as the one presented in the previous sections, except that now part of the individuals that compose society are myopic, meaning that they do not discount the future when making their private economic decisions (savings and labor supply).

The vote takes place sequentially on the two parameters that characterize the PAYG pension system. Individuals first vote on the Bismarckian factor $(\alpha)$ and then on the size of the pension system $(\tau)$. When they vote, individuals are placed under the "veil of ignorance", meaning that they vote as if they were not myopic and thus rationally anticipate the future.

Two main results emerge from this analysis. First, it is shown that, while a Beveridgean system $(\alpha=0)$ is always chosen in a homogeneous society, a Bismarckian system $(\alpha=1)$ may be adopted in a society composed of both farsighted and myopic individuals. Second, the generosity of the pension system $(\tau)$ is not a monotonic function of the proportion of myopic individuals, as one would expect. The reason is

\footnotetext{
${ }^{16}$ Diamond [1977] emphasized the need for the State to provide a mandatory pension system stemming from the fact that individuals may be myopic and do not save adequately for their retirement.
} 
that the type of the pension system may endogenously switch when the proportion of myopic individuals in society is altered.

\subsubsection{Other dimension of individual heterogeneity: differing life ex- pectancies}

Income heterogeneity is certainly not the only dimension in which individuals differ within each cohort. Differences in life expectancy also play a key role when analyzing the design of pension systems and their political support. We have seen in the previous sections that the redistributiveness of the pension system has an impact on its political support : a redistributive system is likely to be supported by the poor and middle-class workers. It should be clear that a pension system that provides annuities also redistributes from the short-lived to the long-lived. For instance, Coronado et al. [2000], Liebman [2001] in the U.S. case and Bommier et al. [2006] in the French case, have shown that part of income redistribution operated by the pension system is neutralized by mortality differentials. Bommier et al. [2006] also estimated that in France, differential mortality offsets between one fourth and one half of aggregate redistribution. Consequently, longevity is one of the many dimensions, other than productivity, which should affect the design of pension schemes.

De Donder and Hindriks [2002] consider a model in which individuals differ both with respect to productivity and mortality rate. They analyze how the political support for social security depends on the link between contributions and benefits (characterized by the parameter $\alpha$ in the previous sections). Their main finding is that tightening the link between contributions and benefits may lead the median voter to raise the equilibrium contribution tax rate, thereby increasing the distortions associated to the social security program. Borck [2007] also considers individuals heterogenous in income and longevity. He assumes a positive correlation between the two and finds that, depending on the magnitude of this correlation, individually optimal tax rates may increase or decrease with income. Cremer and De Donder [2016] extend these works by endogenizing through a majority vote the Bismarckian factor $(\alpha)$. 


\subsection{Risk-sharing}

In a dynamically efficient economy, a FF system provides a higher return than PAYG in expectation. However fluctuations in the interest rates make investments in the FF system risky. In the absence of private markets for insurance, the PAYG may constitute an insurance device. This occurs when the returns to capital and wages are imperfectly correlated. This argument has been formalized by Bohn [2001] and Krueger and Kubler [2006]. We present here a simple version of the model by Krueger and Kubler [2006]. In this model, agents live two periods but value consumption in the second period only, according to the utility function $u($.$) . The indirect utility$ function writes:

$$
V(\tau)=E(u[(1-\tau) w R+\tau w G]),
$$

where $R$ and $G$ are the (stochastic) returns of savings and PAYG respectively, and $E($.$) is the expectation operator. It is welfare improving to introduce a PAYG$ system if $d V /\left.d \tau\right|_{\tau=0}>0$. With a logarithmic utility function and a joint log-normal distribution for $R$ and $G$, this condition reduces to:

$$
E\left(\frac{G}{R}\right)=\frac{E(G)}{E(R)} \frac{\left[c v(R)^{2}+1\right]}{\left[\rho_{G, R} \times c v(G) \times c v(R)+1\right]}>1,
$$

where $c v$ designates the coefficient of variation and $\rho$ the correlation coefficient. This condition can be met even when the expected return from PAYG is lower than the return of savings. This occurs if the stochastic savings returns are very volatile $(c v(R)$ is large) or the correlation between $G$ and $R$ is small.

\section{Endogenous retirement}

Pensions systems are characterized by three key parameters: the payroll tax rate, the benefit level and the retirement age. So far, we have considered the retirement age to be given and common to all individuals. We address in this section the endogenous determination of the retirement age and envisage two main modeling assumptions: either the retirement age is chosen collectively through a vote; or individuals decide freely when to retire. 


\subsection{Implicit taxation and early retirement}

\subsubsection{The political support for early retirement provisions}

In the last thirty years, most OECD countries have experienced a dramatic drop in the labor force participation of their middle-aged and elderly workers. In the OECD countries, the average labor force participation rate of male workers aged between 55 and 64 years has decreased from $84.2 \%$ in 1960 to $66.8 \%$ in 2015 . The extent to which male elderly workers have decreased their participation in the labor market may also be captured by the reduction in the average retirement age.

A comprehensive study on eleven OECD countries edited by Gruber and Wise [1999] suggests that generous early retirement provisions are largely responsible for this drop in the (male) participation rates. Gruber and Wise [1999] and a parallel study by Blondal and Scarpetta [1998] identify two features of the early retirement provisions, which display a strong correlation with the departure of the elderly workers from the labor force: the early (and normal) retirement age and the tax burden which is imposed on the labor income of the individuals who continue to work after reaching the early retirement age. Gruber and Wise [1999] and Blondal and Scarpetta [1998] argue that individuals are often induced to retire early because of the large implicit tax imposed on continuing to work after early retirement age. Individuals' early retirement decision thus represents the optimal response to the economic incentives provided by the social security system.

Conde-Ruiz and Galasso [2003] develop a positive theory of why early retirement age provisions have been introduced in the first place and sustained over time. They analyze a majority voting game over two dimensions: the payroll tax rate and the decision to introduce or not an early retirement provision. Focusing on the (simultaneous) issue-by-issue voting equilibrium, ${ }^{17}$ they show that early retirement is sustained by a coalition of the young poor and of the old with an incomplete earning history. The latter obviously sustain the system as it makes them eligible to pension benefits. The former vote for early retirement because, due to substitution effects

\footnotetext{
${ }^{17}$ The political process being multidimensional, there is no Condorcet winner (Plott [1967]). A possible solution is to determine the issue-by-issue voting equilibrium (Shepsle [1979]). This consists in deriving the voting equilibrium on each policy (for given the other policy). The full equilibrium is then given by the intersection point of these reaction curves.
} 
between leisure and consumption, they tend to retire earlier than the rich. It should be noted that the equilibrium is self-sustained over time (or subgame perfect) as, by retiring earlier, the current poor young will continue to sustain the system when becoming old.

In a subsequent paper, Conde-Ruiz and Galasso [2004] note the (negative) macroeconomic consequences of early retirement provisions which, by inducing individuals to retire earlier, depress human capital accumulation and growth.

\subsubsection{The implicit taxation on continued activity}

Gruber and Wise [1999] point a second feature of social security, besides the existence of an early retirement age, that induces individuals to retire early: the implicit tax on continued activity created by the pension system. When an individual decides to work one more year, he is deprived of one year of pension benefits. Furthermore he has to pay social security contributions for that year. Additional pension benefits less contributory taxes represent the net social security accrual. When it is negative, the pension system encourages early retirement through an implicit taxation on continued activity. In the words of Crawford and Lilien [1981], the pension system is not marginally fair.

Sheshinski [1978] and Crawford and Lilien [1981] were the first to analyze the individual retirement decision. They show that the income and substitution effects of the implicit tax on continued activity go in opposite directions. Leisure being a normal good, the loss in income generated by the tax induces individuals to work longer. But, faced with a lower price of leisure in terms of consumption, they tend to substitute leisure for consumption, i.e. to retire earlier. Under the common assumption that the substitution dominates the income effect, the implicit taxation built in the pension system encourages individuals to retire earlier.

We present here the model by Crawford and Lilien [1981]. They consider a continuous time model in which individuals work for time 0 to $R$ and then retire from $R$ to $T$. Assuming for simplicity no time discounting, life cycle utility is:

$$
\int_{0}^{R} u\left(c_{t}\right) d t+\int_{R}^{T}\left[u\left(c_{t}\right)+v\right] d t=\int_{0}^{T} u\left(c_{t}\right) d t+(T-R) v
$$


where $v$ is the utility of leisure.

Normalizing wage income to 1 and assuming a zero interest rate and a perfect capital market, individuals wish to equalize consumption in all periods. Thus, the worker's problem can be written as

$$
\max _{R, c} T u(c)+(T-R) v
$$

subject to

$$
T c \leq R(1-\tau)+(T-R) p .
$$

Social security benefits obey the following formula:

$$
p=[(T-R(1-B)) A+R B \tau] /(T-R) .
$$

For $B=1$, social security is marginally fair. For $B=0$, benefits per period are a constant, $p=A$. In such a case, the pension system implicitly taxes individuals: those who work one more year not only have to contribute for that year, but also lose one year of pension benefits. Substituting this formula into the constraint of the individual optimization problem yields:

$$
c \leq(R / T)[1-(1-B)(A+\tau)]+A .
$$

Assuming an interior solution, the conditions for a solution of the individual program are:

$$
u^{\prime}(c) \omega=v
$$

and

$$
c=(R / T) \omega+A,
$$

where $\omega=1-(1-B)(A+\tau)$ is the relative price of leisure in terms of consumption.

Differentiating these conditions, we obtain:

$$
\frac{d R}{d B}=-\left[\frac{R}{\omega}+\frac{T}{\omega^{2}} \frac{u^{\prime}(c)}{u^{\prime \prime}(c)}\right](A+\tau)
$$

An increase of $B$ raises the implicit price of leisure, with an ambiguous effect on $R$. There is a substitution effect, $-T u^{\prime}(c)(A+\tau) / \omega^{2} u^{\prime \prime}(c)$, which tends to delay retirement; and an income effect, $-R(A+\tau) / \omega$, which acts to induce earlier retirement. 
If we make the usual labor supply assumption that the substitution effect of a shift in wages dominates the income effect, then $d R / d B>0$.

Casamatta et al. [2005] develop a model with no income effects. The pension benefit formula is such that total benefits do not depend on the age of retirement. An implicit tax, or bias, is however present in the form of the contributory tax. They prove the existence of an issue-by-issue voting equilibrium with a positive bias. The bias is sustained by the poor (both young and old) who benefit from the (intragenerational) redistribution of the system. Numerical simulations show that the bias chosen at the political equilibrium might be excessive with respect to the second-best optimum.

Casamatta et al. [2006] distinguish between the two components of the implicit tax: the payroll tax rate $\tau$ and the reduction in pension rights, represented by a parameter $\alpha$. When $\alpha>0$ (resp. <0), pension rights decrease (resp. increase) with the retirement age. They show that individuals prefer $\alpha<0$, as well as a Rawlsian or Utilitarian planner. A positive tax is however possible when the planner maximizes a weighted sum of utilities and the weight on the rich is sufficiently high, which corresponds to a political process biased towards the rich. This is indeed the outcome of a "bargaining" process between the poor and the rich. These latter ask for a low $\tau$. In exchange they accept to set a positive $\alpha$, which is a second-best instrument for the poor to redistribute income.

Leroux [2010] considers a model in which individuals differ according to longevity. She studies first a pension system with the retirement age uniformly set by the government. In such a setting the PAYG pension system receives the support of the majority of the voters only if the distribution of longevities is left-skewed. The intuition is clear : as the pension system redistributes from the short-lived (with below average longevity) to the long-lived (above average), it receives the support of the majority of the voters if the median longevity is larger than the mean. She then allows the individuals to decide freely when to retire and finds that voluntary retirement reduces the size of the system (characterized by the payroll tax rate), as the taxation of labor income now generates distortions on the retirement decision. She finally analyzes the impact of an increase in longevity on the majority voting 
equilibrium tax rate: the median voter having a larger life duration, he chooses a larger tax rate. Leroux [2010] shows that this increase in the payroll tax rate is accompanied by a rise in the pension benefit level.

\subsection{Voting on the retirement age}

\subsubsection{One dimensional voting}

Lacomba and Lagos [2007] study the one dimensional vote on the retirement age, mandatory and common to all individuals, while other parameters of the pension system (payroll tax rate, benefit level) are held fixed. The main insight of their analysis is to emphasize the dependency of individually optimal retirement ages on the status quo retirement age. If the status quo retirement age is low, individuals anticipate to receive a small pension for a long period of time and therefore tend to save a lot. Therefore an individual who is close to the (current) retirement age at the time of the vote has accumulated a large wealth. Due to the associated income effect, he will tend to favor a lower retirement age than a young individual at the start of his working life. In the words of Lacomba and Lagos, the status quo retirement age "acts like a magnet".

While Lacomba and Lagos [2007] consider individuals with different income levels, we present here a simplified version with only age heterogeneity (wage income is normalized to 1). Population is assumed to be constant and age uniformly distributed on $[0, T]$. The interest rate is assumed to be 0 and individuals do not discount the future. The vote on the legal retirement age takes place at an arbitrary moment of time $t$. It is unanticipated and the newly voted retirement age is believed by everybody to remain permanent. Denoting $R^{s q}$ the retirement age before the vote, accumulated wealth of an aged $a$ worker at the time of the vote is

$$
\pi(a)=a\left(1-\tau-c\left(R^{s q} ; 0\right)\right)
$$

where $c\left(R^{s q} ; 0\right)$ is planned consumption at the beginning of the life cycle when the anticipated retirement age is $R^{s q}: 18$

$$
c\left(R^{s q} ; 0\right)=\frac{R^{s q}(1-\tau)+\left(T-R^{s q}\right) p\left(R^{s q}\right)}{T} .
$$

\footnotetext{
${ }^{18}$ Remind that, with a 0 interest and discount rates, individuals optimally choose a constant stream of consumption.
} 
Substituting this expression in the former, we get:

$$
\pi(a)=a\left(\frac{T-R^{s q}}{T}\right)\left(1-\tau-p\left(R^{s q}\right)\right) .
$$

The level of pension benefits, for given $\tau$ and $R$, is determined by the budget constraint of the pension system:

$$
p(R)=\frac{\tau R}{T-R}
$$

Replacing $p\left(R^{s q}\right)$ in the previous expression gives

$$
\pi(a)=a\left(1-\tau-\frac{R^{s q}}{T}\right) .
$$

Accumulated wealth thus depends on age, life expectancy, the payroll tax rate and the status quo retirement age.

We now turn to the preferred retirement ages of the different individuals.

The retirees It is assumed that the retirees do not return to work if the newly voted retirement age is lower than their age. Therefore postponing the retirement age is always favorable to the retirees, as the number of contributors increases and there are fewer retirees who receive a pension. This implies that the retirees always vote for the largest possible retirement age.

The workers First of all, it is clear that the workers never prefer a retirement age lower than their own age. We therefore have $R^{*}(a) \geq a$, where $R^{*}(a)$ is the optimal retirement age of an aged $a$ worker. Indeed choosing $R^{*}(a)<a$ or $R^{*}(a)=a$ in both cases result in these individuals being on retirement. But in the second case the dependency ratio is lower, meaning a higher level of pension benefits.

The optimal consumption decision of an aged $a$ individual when the retirement age is $R$ is:

$$
\begin{aligned}
c(R ; a) & =\frac{(R-a)(1-\tau)+(T-R) p(R)+\pi(a)}{T-a} \\
& =\frac{R-a(1-\tau)+\pi(a)}{T-a} \\
& =\frac{R-(a / T) R^{s q}}{T-a},
\end{aligned}
$$


and his indirect utility function:

$$
V(R ; a)=(T-a) u(c(R ; a))+(T-R) v .
$$

The first-order condition on $R$ is

$$
u^{\prime}(c)-v=0 .
$$

Differentiating, this implies

$$
\frac{\partial R^{*}}{\partial a}=\frac{R^{s q}-R^{*}}{T-a} \text { if } R^{*}(a)>a .
$$

Then two cases are possible (see figure). Either $R^{*}\left(R^{s q}\right)>R^{s q}$, in which case optimal retirement ages decrease with age, or $R^{*}\left(R^{s q}\right)=R^{s q}$ and the converse holds.

\section{[INSERT FIGURE 1 HERE]}

The status quo retirement age acts as a magnet: as workers get older, their optimal legal retirement ages are closer to the status quo age. The reason is the following. Denote $\tilde{R}=R^{*}(0)$ the optimal retirement age at birth. Consider the case where $\tilde{R}>R^{s q}$ and suppose that all the workers have the same optimal retirement age: $R^{*}(a)=\tilde{R}$. In such a case, optimal consumption levels would be increasing with age (simply differentiate (7) with respect to $a$ ). But this would violate the first-order condition (8), which implies that, at their optimal retirement age, all the workers have the same consumption level. To attain this optimal consumption level, older workers vote for a lower retirement age. In less technical terms, older workers, under the status quo retirement age, have over-accumulated with respect to the newly born. They thus vote for a lower retirement age to achieve the desired life cycle consumption level. A symmetric reasoning can be made for the case $\tilde{R}<R^{s q}$.

Aggregation of preferences through majority voting It can be shown that preferences are single-peaked, implying the existence of a Condorcet winner. If optimal retirement ages increase with age, a coalition of the retirees and middleage workers will join to support a higher retirement age. For decreasing optimal retirement ages, the retirees will form a coalition with the youngest workers. 
Population ageing Lacomba and Lagos [2006] analyze the impact of a change in the fertility rate on the optimal retirement age of individuals at the beginning of the life-cycle. We present here a simplified two-period model, in which individuals spend a fraction $1-z$ of the second period on retirement ( $z$ is thus interpreted as the retirement age). ${ }^{19}$

Life cycle utility is

$$
\begin{gathered}
u\left(c_{t}^{y}\right)+\beta\left[u\left(c_{t+1}^{o}\right)+v(1-z)\right] \\
=u(1-\tau-s)+\beta[u(s(1+r)+z(1-\tau)+p(1-z))+v(1-z)],
\end{gathered}
$$

where $\beta=1 /(1+r)$. Assuming a perfect capital market, individuals equalize firstand second-period consumptions:

$$
c=\frac{(1-\tau)(1+r+z)+p(1-z)}{2+r}
$$

and the optimal retirement age solves

$$
\max _{z} \frac{2+r}{1+r} u(c)+\frac{1}{1+r} v(1-z)
$$

The budget constraint of the PAYG system is

$$
\begin{aligned}
N^{y} \tau+N^{o} z \tau & =N^{o}(1-z) p \\
\Leftrightarrow \quad \tau(1+n+z) & =(1-z) p .
\end{aligned}
$$

In a defined contribution (DC) pension system, the pension benefit level depends on the value of the tax rate:

$$
p(\tau)=\frac{\tau(1+n+z)}{(1-z)}
$$

while in a defined benefit (DB) system, this is the tax rate that adjusts:

$$
\tau(p)=\frac{(1-z) p}{(1+n+z)}
$$

Using (9), we obtain

$$
c^{\tau}=\frac{1+r+z-\tau(r-n)}{2+r}
$$

\footnotetext{
${ }^{19}$ Contrarily to the continuous time model analyzed above, we consider non-zero discount and interest rates, denoted respectively $\beta$ and $r$.
} 
and

$$
c^{p}=\frac{1+r+z-\frac{(1-z) p}{(1+n+z)}(r-n)}{2+r},
$$

where $c^{\tau}$ and $c^{p}$ are the optimal consumption levels in the defined contribution and defined benefit systems respectively. The impact of a change in the retirement age is different in a DB or in a DC system, unless $r=n$. It can indeed be shown that:

$$
\frac{\partial c^{\tau}}{\partial z}=\frac{1}{2+r}
$$

and

$$
\frac{\partial c^{p}}{\partial z}=\left[1+p \frac{2+n}{(1+n+z)^{2}}(r-n)\right] /(2+r) .
$$

The change in consumption in a DC system is "neutral": if individuals work one more year, their lifetime consumption increases by $1 /(1+r) .{ }^{20}$ The change is however not neutral in a DB system. As soon as $r>n$, consumption increases by more than the change in income. The reason is that when $p$ is fixed, total pension $p(1-z)$ is reduced when individuals postpone retirement. This means that the amount of resources devoted to the PAYG system (the "size" of the system) decreases. These resources can be invested at a better return in private savings when $r>n$.

Observe also that the optimal retirement age differs in DC and DB. This latter is the solution of the first-order condition:

$$
(2+r) \frac{\partial c}{\partial z} u^{\prime}(c)-v=0 .
$$

Looking at conditions (10) and (11), it is clear that $\partial c^{\tau} / \partial z<\partial c^{p} / \partial z$ (as soon as $r>n$ ) and thus that the optimal retirement age is larger in a DB system. The reason for such a difference between the two systems is that the DB system is biased in the sense that the net pension wealth $p(1-z)-\tau z$ (equal to $\tau(1+n)$ from the budget constraint) varies with $z$. In a DC system on the contrary it is fixed and depends on the chosen value of the contribution rate $\tau$.

The impact of a change in the population growth rate in a DC system is straightforward:

$$
\frac{\partial z^{*}}{\partial n}=\frac{\tau u^{\prime \prime}(c)}{-D_{z}} \frac{1}{2+r}<0 .
$$

${ }^{20}$ Lifetime consumption is $c+c /(1+r)=c((2+r) /(1+r))$. 
The intuition is simple. Due to a drop in the fertility rate, the PAYG system has a lower rate of return. Therefore, lifetime consumption is reduced. Leisure being a normal good, individuals choose to postpone retirement to counter this (negative) income shock.

One can show (after quite tedious calculations) that the same conclusion holds in a DB system: the optimal retirement age is decreasing with the rate of population growth.

\subsubsection{Joint determination of the retirement age and the contribution rate}

Galasso [2008] considers the joint determination of the size of the PAYG system (given by the contribution rate) and the retirement age through an issue-by-issue voting procedure. He calibrates the model on economic data for the year 2000 in various OECD countries and uses forecasted values to construct the politicoeconomic equilibrium in year $2050{ }^{21}$

Due to population ageing and absent any political reaction (i.e. for unchanged contribution rate and retirement age), the economy has to adjust: pension benefits drop and individuals increase their savings, making the stock of capital larger. As a consequence, wages increase and the interest rates fall dramatically. These aggregate effects are dampened when political reactions are taken into account.

The political equilibrium is given by the intersection of two reaction curves: $\tau(R)$, the majority voting tax rate for a given retirement age and $R(\tau)$, the majority voting retirement age for a given tax rate. To understand the impact of population ageing, one thus need to analyze how each of these reaction curves is affected by ageing.

How does the majority voting tax rate react to population ageing? For a given retirement age, population ageing is known to have two opposite economic and political effects on the determination of the contribution rate (see Casamatta et al. [2000], Razin et al. [2002], Galasso and Profeta [2004], Galasso and Profeta [2007]). ${ }^{22}$

\footnotetext{
${ }^{21}$ See subsection 6.2.2 for a quantitative assessment of the effects of ageing when contribution rates and retirement age are voted upon at the same time, on a model very similar to the one discussed here.

${ }^{22}$ These effects have been studied in section 2.2.2.
} 
The political effect is positive: the median voter being older, he chooses a larger tax rate. The economic effect is however ambiguous and depends on the comparison of an income and a substitution effects. Simulation results reported in Galasso suggest that the political push dominates in all countries: ageing shifts the reaction function $\tau(R)$ upward.

What is the effect of ageing on the majority voting retirement age ? Again, one should compare an economic and a political effects. The economic effect has been studied in the previous section: ageing reduces the average profitability from social security, which generates a reduction in the lifetime income of all generations. This negative income effect encourages individuals to postpone retirement. The political effect is however ambiguous: the analysis in section 3.2.1 suggests that, the median voter being older, he may choose a larger or lower retirement age, depending on the status quo retirement age. In the numerical simulations presented by Galasso [2008], ageing generates a political push for postponing retirement: the reaction functions $R(\tau)$ shifts upward.

Two main insights emerge from this simulation exercise. First, the retirement age increases dramatically in all countries. As emphasized above, the income effect associated to ageing pushes for delaying retirement. This is reinforced by the economic consequences of ageing: the opportunity cost of retiring, as represented by the wage rate, increases. Second, in all countries but Italy, both the contribution rate and the level of benefits increase. The rise in the contribution rate is not that surprising: in the face of ageing, individuals must invest more in social security to maintain a decent level of retirement consumption. Moreover the interest rate is lowered, reducing the gap between the profitability of savings and PAYG social security. The increase in the levels of benefits is more surprising. While it is difficult to disentangle the various effects at play in these numerical simulations, the ageing of the median voter, and the associated increased demand for social security, is certainly one of the main reasons driving this result. 


\section{The social contract}

\subsection{Sustainability of the PAYG system}

In the Browning analysis and subsequent papers on the vote over pensions, it is assumed that agents vote once and for all. This assumption, while convenient, is strong. Why young individuals should support the system, if the tax rate is re-voted tomorrow and there is therefore no direct link between the contributions they make and the benefits they receive? The answer is that there exists an implicit contract between generations: the young support the system because of the threat to be punished by future generations. If they break down the system, they incur the risk of receiving no pension benefits in old age (although of course they could rely on savings). This idea has been first formalized by Hammond [1975] and then adapted to the pension game by Sjoblom [1985] and Boldrin and Rustichini [2000].

To illustrate the argument, we consider an infinitely repeated voting game with individuals living two periods. Assuming a positive rate of population growth, the young are more numerous than the old and therefore are decisive in the vote. Indirect life cycle utility is denoted $v_{t}^{y}\left(\tau_{t}, \tau_{t+1}\right)$.

Consider the sequence of tax rates $\left(\tau_{i}^{*}\right)_{i=1}^{\infty}$ and the strategies ${ }^{23}$

$$
\sigma_{s}^{y}= \begin{cases}\tau_{s}^{*} & \text { if } \tau_{s-i}=\tau_{s-i}^{*} \text { for all } i=1, \ldots, s-1 \\ 0 & \text { otherwise. }\end{cases}
$$

The social contract prescribes the choice of $\tau_{i}^{*}$. According to this strategy profile, young individuals comply with this implicit contract if everybody has done the same in the past. Otherwise, they break the contract by choosing a 0 tax rate.

Denote $\left(v_{i}^{*}\right)_{i=1}^{\infty}$ the resulting payoffs for the young. We have to check two conditions to obtain a subgame perfect equilibrium.

1) No player should want to deviate in any time period. The best deviation for a young in period $s$ is to choose $\tau_{s}=0$. By choosing a tax rate different from $\tau_{s}^{*}$, he breaks the contract and receives no pension. He has therefore no interest in contributing to the system. Consequently, if $v_{s}^{*} \geq v_{s}^{y}(0,0)$, a young individual has no interest in breaking the contract.

\footnotetext{
${ }^{23}$ Players of this game are generations of individuals. In other words, it is assumed that there exists a coordination mechanism for individuals belonging to any given generation.
} 
2) Subgame perfection: if player $t$ deviates, player $t+1$ must have an incentive to punish him. Because once a player has deviated, the system is permanently abolished, player $t+1$ will receive no pension and should thus not contribute: punishment is credible.

This leads to the conclusion that the strategies above constitute a subgame perfect equilibrium as soon as $v_{s}^{*} \geq v_{s}^{y}(0,0), \forall s$. This condition simply states that the young are better off with the social security system implemented. It is satisfied in the different cases described in section $2 .{ }^{24}$ It should however be kept in mind that there exist many other equilibria. ${ }^{25}$ This game thus generates a high degree of indeterminacy.

\subsection{Dynamics of the political equilibrium}

In the recent historical experience of many countries the immediate cause for the general alarm surrounding the social security system seems to be the long run fall in the growth rates of population and labor productivity. Boldrin and Rustichini [2000] show that, even if one knows that the PAYG system will be dismantled in a finite future and therefore that some generation will contribute to it but will never receive any benefit, this system can be sustained by a majority of the voters. This follows from introducing in the previous game a stochastic process for the growth rate of population. They consider a sequence of growth rates $\{n(j)\}_{j=0}^{\infty}$ satisfying $n(j+1)<n(j)$, for all $j$, and $\lim _{j \rightarrow \infty} n(j)=0$, and a transition probability

$$
\begin{aligned}
\operatorname{Pr}\left(n_{t+1}=n(j) \mid n_{t}=n(j)\right) & =1-p \\
\operatorname{Pr}\left(n_{t+1}=n(j+1) \mid n_{t}=n(j)\right) & =p,
\end{aligned}
$$

with $0<p<1$.

With a linear production function, $f(k)=a k+b$, and logarithmic utility, they show that there exists an equilibrium with a sequence of tax rates $\{\tau(j)\}_{j=0}^{\infty}$, such that $\tau(j)>0$ for some $j$ and $\tau(j+1)<\tau(j)$ for all $j$. This means that a PAYG is

\footnotetext{
${ }^{24}$ This equilibrium could easily be extended to the case of three generations analyzed by Browning [1975].

${ }^{25}$ In particular, no social security is always an equilibrium : if a player believes that the following generation will not contribute, it is optimal not to contribute, even if it is Pareto improving that every generation contributes.
} 
sustainable even though one knows that it will be dismantled for sure in the future (but not when). The condition for having this equilibrium is $a<(1-p)\left(1+n_{0}\right)$. Noting that $a=1+r$ in this model, the intuition is clear: even though there is a risk of not receiving pensions in the next period, the expected return of the PAYG system dominates private savings (as long as $a<(1-p)\left(1+n_{t}\right)$ ).

\subsection{Markov perfect equilibria}

The game described in section 4 has many equilibria. Furthermore, it is quite poor in making predictions and does not allow to do comparative statics. A way to select among these equilibria is to consider the concept of Markov perfect equilibrium. A Markov strategy is such that the action played in a given period only depends on some fundamental state variables, such as the level of the capital stock or the ratio of the number of retirees to workers. ${ }^{26}$ This approach has generated a considerable interest in the last years. We review in the next sections the main work in this direction.

\subsection{A median voter model with capital as the state variable}

Forni [2005] has developed a model close to Boldrin and Rustichini [2000]. It is a standard two-period OLG model. Agents work, consume, save and pay taxes in the first period. They retire, consume, and receive old age benefits in the second one.

A logarithmic utility function is assumed, as well as a Cobb-Douglas production function: $Y=K^{\alpha} L^{1-\alpha}$. In per capita terms: $y=k^{\alpha}$ with $k=K / L$. It is assumed that capital depreciates completely in one period.

The utility maximization program of a young agent in period $t$ is:

$$
\max _{c_{t}^{y}, c_{t+1}^{o}} u\left(c_{t}^{y}, c_{t+1}^{o}\right)=\ln \left(c_{t}^{y}\right)+\beta \ln \left(c_{t+1}^{o}\right)
$$

subject to

$$
\begin{aligned}
c_{t}^{y} & =w_{t}\left(1-\tau_{t}\right)-s_{t} \\
c_{t+1}^{o} & =s_{t}\left(1+r_{t+1}\right)+p_{t+1} .
\end{aligned}
$$

${ }^{26}$ See Fudenberg and Tirole [1991] for a precise definition of Markov Equilibria. 
Given the Cobb-Douglas production function, the profit maximizing conditions imply that:

$$
w_{t}=(1-\alpha) k_{t}
$$

and

$$
r_{t+1}=\alpha k_{t+1}^{\alpha-1}-1 \text {. }
$$

The budget constraint of the PAYG system also implies:

$$
p_{t+1}=\tau_{t+1} w_{t+1}(1+n) .
$$

With a logarithmic utility function, the utility maximization program has closedform solutions:

$$
\begin{aligned}
c_{t}^{y} & =\left(\frac{1}{1+\beta}\right)\left[w_{t}\left(1-\tau_{t}\right)+\frac{p_{t+1}}{1+r_{t+1}}\right] \\
c_{t+1}^{o} & =\left(\frac{\beta}{1+\beta}\right)\left[w_{t}\left(1-\tau_{t}\right)\left(1+r_{t+1}\right)+p_{t+1}\right] \\
s_{t} & =\left(\frac{1}{1+\beta}\right)\left[\beta w_{t}\left(1-\tau_{t}\right)\left(1+r_{t+1}\right)-\frac{p_{t+1}}{1+r_{t+1}}\right] .
\end{aligned}
$$

The last equilibrium condition is the capital formation dynamic equation:

$$
(1+n) k_{t+1}=s_{t} .
$$

Collective decisions are made through majority voting. The young being more numerous than the old, they decide on the payroll tax rate in each period. Strategies are assumed to be Markov and moreover to be time-invariant: the policy function is of the type $\tau_{t}=\tau\left(k_{t}\right)$. In words, the payroll tax rate chosen in period $t$ only depends on the capital stock in this period.

Using the optimality conditions (12), (13), (15), (16), ( 17) as well as the PAYG budget constraint (14), we can write the indirect utility function of the young in period $t$ as $\Psi\left(k_{t}, \tau\left(k_{t}\right), \tilde{\tau}\left(k_{t+1}\right)\right)$. This depends on the capital stock in periods $t$ and $t+1$, on the policy function chosen in period $t, \tau($.$) , and on the expectation on the$ next period policy function, $\tilde{\tau}($.$) .$

The optimal strategy of the median voter in period $t$ (a young) solves the following program:

$$
\max _{0<\tau(.)<1} \Psi\left(k_{t}, \tau\left(k_{t}\right), \tilde{\tau}\left(k_{t+1}\right)\right),
$$


subject to

$$
k_{t+1}=\Phi\left(k_{t}, \tau\left(k_{t}\right)\right)
$$

where this latter condition represents the capital formation equation (18), after substitution of the conditions (12), (13) and (14).

The allocation obtained is a (stationary) Markov perfect equilibrium if the policy function $\tau($.$) is a fixed point of the mapping from \tilde{\tau}($.$) to \tau($.$) , where \tau($.$) is the$ solution of the median voter's problem (19). In other words, an equilibrium occurs if there exists a differentiable policy function that solves the median voter's program and is such that $\tau()=.\tilde{\tau}($.$) .$

Forni [2005] shows that the equilibrium policy function is:

$$
\tau(k)=\left(\frac{\alpha}{1-\alpha}\right)\left[C k^{-(1+\beta \alpha) /(1+\beta)}-1\right]
$$

where $C \geq 0$ is a constant. Therefore there is a continuum of equilibria indexed by the free parameter $C$. The equilibrium policy function is non-increasing in $k$. To see this, suppose on the contrary that the payroll tax rate increases with $k$. Then young individuals should strategically increase savings to attract greater old-age benefits in the next period. But this cannot be an equilibrium, as the perspective of a larger benefit when old induces the young to reduce the level of savings.

In this setting, it is shown that, for some parameters values, there exist equilibria with social security. The reason why the young may sustain the system is the following. When they increase their contribution to the PAYG system, the young save less. The capital stock in the next period being lower, the payroll tax rate and thus the level of pension benefits increase. Conversely, a downsizing of the pension system in a given period is followed by a "punishment" in the next period, taking the form of a reduction in pension benefits. This can be seen as a continuous version of Boldrin and Rustichini [2000], in which the young decision consists in keeping the pension system or dismantling it. The equilibrium strategy, which implies a reduction in payroll taxes as the capital stock increases, is simply the implementation of a punishment strategy in a Markovian context. ${ }^{27}$

\footnotetext{
${ }^{27}$ Another reason why the young may support social security is the general equilibrium effect on prices: a drop in the capital stock makes the interest rate increase. This effect has been pointed out in the literature by Boldrin and Rustichini [2000] or Cooley and Soares [1999].
} 
What is the effect of a demographic change in this model? An increase in the rate of population growth $n$ leads to a higher rate of return of the PAYG system. ${ }^{28}$ This in turn induces the young to reduce their savings. The steady state capital stock is thus reduced and the size of the pension system (i.e. the contribution rate) increased.

\subsection{Probabilistic voting}

Gonzalez-Eiras and Niepelt [2008] study a model formally close to Forni [2005]. The main difference lies in the modeling of the political process in each period. While Forni [2005] considers simple majority voting, Gonzalez-Eiras and Niepelt [2008] use a probabilistic voting model. This results in the government maximizing a weighted sum of the welfare of the young and the old in each period. They focus on a particular Markov equilibrium, in which the equilibrium tax rate does not depend on the savings level. Therefore, reputational effects are absent of the model. The only reason why the young may sustain the pension system is because it allows to "manipulate" prices: a larger payroll tax rate depress savings, implying a larger interest rate.

With a logarithmic utility function and a Cobb-Douglas production function, the model predicts that, when the population growth rate decreases, the payroll tax rate and the share of pensions in GDP increase, but the social security benefit per retiree may eventually decline. The main driving force behind these results is that, with population ageing, the old gets more political power. This explains the rising tax rate. With more retirees however this may not be sufficient to give a higher pension to all of them, all the more that the tax base (the wage rate) shrinks because of a reduced capital accumulation. Calibrating the model to the US economy, it is found that payroll tax rates should increase up to $16 \%$ in 2050 , accompanied by a slight reduction in the pensions level (less than 9\%).

\subsection{The evolution of retirement}

Conde-Ruiz et al. [2013] study a three-period OLG model, with young, adult and

\footnotetext{
${ }^{28}$ Observe that in this simple two-period model, this does not affect the "identity" of the median voter, who is always a young individual.
} 
old individuals living in each period. The young work and provide labor $l$ on the intensive margin. The adults provide labor $z$ on the extensive margin: this corresponds to the age of retirement. It is assumed for simplicity that adults do not receive pensions. The wages of the young and the adults are denoted $w^{y}$ and $w^{a}$ respectively. Old individuals are on retirement and receive a pension $p$. Population grows at a rate $n$.

Under the assumption that individuals only consume when retired, old-age consumption of an individual born in period $t$ is:

$$
c_{t+2}=\left(1-\tau_{t}\right) l_{t} w_{t}^{y}(1+r)^{2}+\left(1-\tau_{t+1}\right) z_{t+1} w_{t+1}^{a}(1+r)+p_{t+2} .
$$

Individuals want to consume as much as possible. They also incur some disutility of work. Their utility function is thus:

$$
U\left(c_{t+2}, z_{t+1}, l_{t}\right)=c_{t+2}-\frac{z_{t+1}^{2}}{2 \gamma} w_{t+1}^{a}-\frac{l_{t}^{2}}{2 \alpha} w_{t}^{y} .
$$

Assuming $\alpha=1 /(1+r)^{2}$ and $\gamma=1 /(1+r)$, optimal labor supply functions are:

$$
\hat{l}_{t}=1-\tau_{t}
$$

and

$$
\hat{z}_{t+1}=1-\tau_{t+1}
$$

Assuming that the PAYG system is budget balanced, the pension benefit is:

$$
p_{t}=\tau_{t}\left(1-\tau_{t}\right)\left(1+n_{t-1}\right) \bar{w}_{t},
$$

where $\bar{w}_{t}=\left(1+n_{t}\right) w_{t}^{y}+w_{t}^{a}$.

Substituting the optimal labor functions and pension benefit level into the utility function, we get the indirect utility function of an adult individual at time $t$, $V^{a}\left(\tau_{t-1}, \tau_{t}, \tau_{t+1}\right)$.

The authors determine the Markov perfect equilibrium of the repeated voting game on payroll tax rates, in which the state variable is the share of elderly retirees in the population. In every period $t$, the median voter in each generation - an adult individual as long as $n_{t}\left(1+n_{t-1}\right)<1$ - decides his preferred social security system (i.e. the tax rate $\tau_{t}$ ). In taking his decision, he expects the future social security 
tax rate to depend on the current level of early retirement, according to a function $\tau_{t+1}=Q\left(z_{t}\right)$. Therefore the median voter's optimal decision can be obtained by maximizing his life cycle utility with respect to $\tau_{t}$ and given expectations on the next period policy function $\tau_{t+1}=Q\left(Z\left(\tau_{t}\right)\right)$ :

$$
\max _{\tau_{t}} V^{a}\left(\tau_{t-1}, \tau_{t}, Q\left(Z\left(\tau_{t}\right)\right)\right)
$$

A Markov political equilibrium is then a pair of functions $(Q, Z)$ such that:

(i) $Q\left(z_{t-1}\right)=\arg \max _{\tau_{t}} V^{a}\left(\tau_{t-1}, \tau_{t}, Q\left(Z\left(\tau_{t}\right)\right)\right)$

(ii) $Z\left(\tau_{t}\right)=1-\tau_{t}$

The link between generations is made though the function $Q$ : when choosing the tax rate, the period $t$ median voter affects the share of early retirees (through the function $Z$ ). This in turn has an influence of the period $t+1$ median voter's choice.

Conde-Ruiz et al. [2013] show that the equilibrium policy function $Q$ satisfies:

$$
\begin{aligned}
\tau_{t+1}=Q\left(Z\left(\tau_{t}\right)\right) & =\frac{1}{2}-\frac{1}{2} \sqrt{1-\frac{2 A-2(1+r) w_{t}^{a} Z\left(\tau_{t}\right)^{2}}{\left(1+n_{t}\right) \bar{w}_{t+1}}} \\
& =\frac{1}{2}-\frac{1}{2} \sqrt{1-\frac{2 A-2(1+r) w_{t}^{a}\left(1-\tau_{t}\right)^{2}}{\left(1+n_{t}\right) \bar{w}_{t+1}}}
\end{aligned}
$$

where $A$ is a free parameter.

A current increase in the social security contribution rate leads to more current early retirement - by increasing the implicit tax on continued activity - which in turn creates expectations for more social security contributions - and hence more early retirement - in the future.

The equilibrium path converges to a stable steady state with a positive social security contribution rate and early retirement.

What is the effect of ageing, caused by a reduction of the fertility rate, in this model ? Suppose that the median voter at time $t$ learns that population growth will permanently drop from the following period on: $n_{t+i}<n_{t} \forall i>0$. Since no change occurs in the policy function at time $t-\tau_{t}=Q\left(Z\left(\tau_{t-1}\right)\right)$ only depends on $n_{t-1}$ and $n_{t}$ - the social security contribution rate is set in accordance with the expectations of the period $t-1$ median voter. Yet the tax rate in $t+1$ depends on $n_{t+1}$ and is thus modified, as well as the whole sequence of future tax rates. Starting from a steady state (with $\bar{\tau}, \bar{p}$ and $\bar{z}$ ), the contribution rate increases, $\tau_{t+1}>\tau_{t}=\bar{\tau}$, people retire 
earlier, $z_{t+1}<z_{t}=\bar{z}$, while the per-capita pension is unaffected, $p_{t+1}=p_{t}=\bar{p}$. At steady state, the contribution rate is larger, $\bar{\tau}^{\prime}>\bar{\tau}$, implying $\bar{z}^{\prime}<\bar{z}$.

This political economy analysis thus suggests that ageing will lead to a larger social security system and more early retirement. This result was however obtained with a quasi-linear utility function with only substitution effects on labor supply taken into account. Conde-Ruiz et al. [2013] note that the introduction of income effects may mitigate these results: the loss of income following the drop in the PAYG rate of return induces individuals to work more and therefore to postpone retirement.

\section{The transition to a Fully Funded system}

Previous sections considered only parametric reforms of the PAYG system, that is modifications of the parameters that characterize the pension system. Another type of reform, which we will call systemic, would consist in transitioning to a FF system, where current contribution are saved to provide for benefits later in the life cycle.

Due to the drop in fertility rates, population grows at a slower rate. This implies a lower rate of return for the PAYG system. Therefore many believe that it is desirable to move to a FF system. The mere comparison of steady states is however misleading. It has been shown that, absent labor supply distortions, the transition to a FF system cannot be Pareto-improving (Breyer [1989]): when moving to the FF system, the implicit debt of the PAYG system is simply made explicit; the PAYG system is nothing more than an intergenerational redistribution scheme. In other words, some generations gain from the reform but others lose. Only when there are some labor market distortions can the reform yield a Pareto-improvement (Homburg [1990], Breyer and Straub [1993], Rangel [1997]).

We illustrate this argument with a simple two-period representative agent OLG model in a small open economy. We denote $N_{t}^{y}$ and $N_{t}^{o}$ the number of young and old individuals in period $t$. Population grows at a constant rate $n$, so that $N_{t}^{y}=(1+n) N_{t}^{o}$. Wages are assumed to be constant (normalized to 1). Consider a steady state with a constant contribution rate $\tau$ and constant labor supply $l$. The PAYG pension benefit in this steady state is:

$$
p^{\text {payg }}=\tau l(1+n) .
$$


Clearly, if $r>n$, individuals would be better off in the steady state with a FF system in which they invest $\tau l$ in every period. Their payment when young would be the same, namely $\tau l$, and the pension benefit level would be:

$$
p^{f f}=\tau l(1+r)
$$

However this is not the answer to the question we are interested in. We wish to know whether, starting from a steady state with a PAYG system, it is possible to operate a transition to a FF system that improves the welfare of all generations. We now show that it is possible to make the transition in a Pareto-neutral way.

Consider a reform that occurs at time $T$. With a fixed labor supply $l$ (normalized to 1 ), the mechanism to obtain a welfare-neutral transition is the following. The retirees at time $T$ receive the promised pension $p^{\text {payg }}$ so that they are indifferent between reforming the pension system or not. This pension is financed by a mix of time $T$ workers contributions and government debt. The new contribution rate at time $T$ is such that:

$$
\begin{aligned}
\tau_{T}^{*} & =\tau-p^{\text {payg }} /(1+r) \\
& =\tau-\tau \frac{1+n}{1+r}
\end{aligned}
$$

Suppose that the government borrows $N_{T}^{y} \tau(1+n) /(1+r)$ in period $T$ and that the time $T$ workers invest $\tau(1+n) /(1+r)$ in the FF system. Their pension in period $T+1$ is thus $\tau(1+n)=p^{p a y g}$ and their payment in period $T$ is $\tau_{T}^{*}+\tau(1+n) /(1+r)=\tau$. They are thus indifferent between the PAYG and the FF system.

Suppose now that time $T+1$ workers pay a tax to reimbourse part of the government debt. This tax is:

$$
\tau_{T+1}^{*}=\tau-\tau \frac{1+n}{1+r}
$$

Moreover they invest $\tau(1+n) /(1+r)$ in the FF system. Their total payment when young is thus $\tau$ and their pension benefit when old (in period $T+2$ ) is $\tau(1+n)=$ $p^{\text {payg }}$. Therefore generation $T+1$ gets the same life cycle utility as in the initial steady state with the PAYG system. The government needs to borrow the difference between its debt, $N_{T}^{y} \tau(1+n) /(1+r)$, and the taxes paid by the young in period $T+1, N_{T+1}^{y} \tau_{T+1}^{*}$. This difference is equal to $N_{T+1}^{y} \tau(1+n) /(1+r)$. 
This process can be repeated infinitely with all generations having the same welfare level in the initial steady state with the PAYG system and in the new one with the FF system. We thus have presented a Pareto-neutral transition to a FF system when labor supply is fixed. This suggests that no Pareto improvement is possible (the reader can refer to Breyer [1989] for a formal proof).

What happens when labor supply is endogenous ? It should be noted that the tax rate in the new scheme, $\tau_{t}^{*}$, is lower than $\tau$. This implies that the new scheme is less distortive and that it is therefore possible to use this efficiency gain to raise strictly the welfare of all generations. Homburg [1990] goes even further by noting that these efficiency gains can be used to reimburse the government debt in finite time. It is thus possible to completely abolish PAYG and to restore the economy's net wealth to the level which is associated with a pure capital reserve system.

Conesa and Garriga [2008] use these results to construct numerical simulations in which all generations benefit from the reform (transition generations receive no pension but are compensated with a debt-financed transfer). ${ }^{29}$ They however consider a representative-agent economy. When individuals differ with respect to labor income within cohorts, efficiency gains have to be compared to the insurance benefit of the PAYG system (Conesa and Krueger [1999], Nishiyama and Smetters [2007]).

\section{Quantitative analysis}

\subsection{Empirical estimations}

Several empirical estimations of the relationship between the age structure of population and the share of income devoted to pension programs - and other types of social spending as well - have been conducted in recent years. We detail their most salient features hereafter.

Lindert [1994] provides a long-term, historical point of view on the link between ageing and pension transfers, by providing panel estimates on industrial countries for the period 1880-1930. The role played by demographics to explain the rise in

\footnotetext{
${ }^{29}$ Before them, all quantitative analyzes have found welfare gains in the long run, but losses for the transition generations. Conesa and Garriga [2009] follow the same optimal taxation approach. They however do not address the question of the transition to a FF system, but maintain the PAYG system and look for the optimal adjustment of its parameters following a temporary demographic shock.
} 
social spending over the period is measured, including controls for income levels and growth, political determinants (indicators of democratization, women's suffrage, rate of executive turnover) and religious affiliation. He shows that the share of population aged 65 and more had a positive impact on the share of GDP devoted to total social spending (a notion that encompasses all social transfers such as pensions, health care, etc. and educational spending): this type of evidence concurs with the insight that longevity should induce an increase in total spending (and thus taxation). The effect on social transfers only is also positive. On the contrary, the share of population aged between 20 and 39 has a significant negative impact on the share of social transfers in GDP. The main results are confirmed in a similar analysis of the 19601980 period by Lindert [1996]: over this period, a higher share of older people in the total population exerts a positive impact on the share of GDP spent on pensions, while the share of school-age individuals does not affect significantly the share of educational spending on GDP. We also briefly mention Durevall and Henrekson [2011] as a more recent analysis of the relationship between social spending and the age structure of the population based on long-run historical data.

Breyer and Craig [1997] conduct an analysis on 20 OECD countries over the 1960-1990 period, using pension spending over GDP or average pension per capita as dependent variables. Among the explanatory variables, the age of the median voter in each country and the ratio of the population aged 40-60 to the elderly are meant to capture the effects of ageing. A strong and significantly positive effect of the age of the median voter on the size of pension programs is found in all specifications. The estimate implies that an increase in median voter age by one year would lead to a $0.5 \%$ increase in the share of social security payments to GDP, to be compared with a sample mean of $9 \%$ for this variable. The support ratio (reduced to the $40-60$ age group for the numerator) has a negative effect on pension program size, when it is added into the regression. Another paper also using OECD panel data, Sanz and Velazquez [2007], indicates that public spending in several areas of government (social welfare, health, but also education and defense) increases with the share of the elderly of the population. However, benefits per capita are not reported to be affected in any significant way. Profeta [2002] reports similar findings using a large 
cross-country dataset which is not restricted to OECD countries: when the share of elderly in the population increases, total social security expenditure increase. The share of elderly in the overall population has more contrasted effects at the individual level, however: while the average length in retirement is reported to increase, and the labor force participation of the elderly decreases when population ages, the pension annuity is, again, not affected.

The empirical relationship between population structure and pension spending has been at the center of a controversy, started by a paper by Razin et al. [2002] . They estimate a panel data of the U.S. and 12 European countries over the period 1965-1992, with the average tax rate on labor income and the per capita transfers (including pensions, unemployment and disability compensation) as dependent variables. The explanatory variables used are the dependency ratio (measured as one minus the share of labor force in the population), a measure of income skewness, real growth in GDP and other controls. Both regressions yield a negative impact of the dependency ratio on the dependent variable. Indeed, in the main specification, a $1 \%$ increase in the dependency ratio is shown to lead to a $0.4 \%$ decline in the labor tax rate: this means that the $4 \%$ decline in the dependency ratio that happened over the 1970-1991 period accounts for roughly $1.5 \%$ of the $11 \%$ increase in the labor tax rate then. Again, all specifications point to a higher dependency ratio leading to lower per capita government transfers: over the same period, the decrease in the dependency ratio accounts for $30 \%$ of the increase in transfers. Razin et al. [2002] also introduce a theoretical model to account for the non-structural relationships they find. In this two-period OLG model, a single labor tax is used to finance a lump-sum transfer to both generations, which is used by the young to acquire education and by the old as a pension. In this context, while the young want some tax to finance their education, the chosen level is limited by the fiscal "leakage" going to the old. Therefore when population growth increases (equivalent in the model to a reduction in the dependency ratio), this leakage is reduced, potentially leading to a higher chosen tax rate if the distortionary effect of taxation is not too strong on the opposite side.

The findings of Razin et al. [2002] have been questioned by Bryant [2003], Disney 
[2007], Simonovits [2007] and Shelton [2008], mostly for the use of the dependency ratio as a measure of population ageing. In particular, Disney [2007] proceeds to a new test of the model introduced by Razin et al. [2002] on a dataset of 21 countries for the 1970s to 1990s decades, redefining the variables used in the regression: the old-age dependency ratio (defined as the share of $65+$ to the 15-64 year-old population) and the inverse of the support ratio (namely, the share of pensioners to people participating to the labor market) are used instead of the simple dependency ratio, and the share of labour taxes in GDP and the average contribution rate to social security. In all specifications, the measures of age dependency are this time positively associated with tax rates, with strong statistical significance in the case of the pension contribution rate: the typical specification indicates that the pension contribution rate paid by workers ${ }^{30}$ would increase by around $0.6 \%$ if the old-age dependency ratio were to be increased by $1 \%$, on average. Moreover, by introducing proxies that capture to which degree social security systems link contributions and entitlements, Disney [2007] shows that the positive relationship between ageing and tax rates becomes weaker when contributions made by individuals start to match less their future entitlements. In the limit case where current contributions bear no link to future benefits (as is the case in the model by Razin et al. [2002] where decision on tax rates is purely static), this relationship may then be reversed. In practice, though, most pension systems around the world entail some actuarial component.

\subsection{Simulating the future political evolution of social security}

\subsubsection{Political sustainability and the evolution of the contribution rates for the current systems}

Galasso [2006] is, to the best of our knowledge, the only successful attempt so far at simulating the evolution of the social security systems of several key countries ${ }^{31}$ until 2050, by taking into account both the economic and the political effects of changes in the age structure of population. ${ }^{32}$ To this end, the author builds a closed-economy

\footnotetext{
${ }^{30}$ In this paper, the contribution rate is defined as the ratio between the social security replacement rate and the support ratio of the pension scheme, and is meant to measure the share of the average worker's labor income that needs to be paid to balance the pension scheme.

${ }^{31}$ The countries concerned by the simulation exercise are: the USA, the UK, Germany, France, Italy and Spain.

${ }^{32}$ It should be noted that Galasso and Profeta [2004] was actually the first attempt at simulating
} 
model with several overlapping generations of agents that differ in age and education, supply work elastically, save and consume. The pension system is modelled in such a way that its budget is balanced in each period, with a fixed age of retirement. The other main institutional features of each national system considered are either held fixed across the years or not taken into account, to ensure tractability. This way, policy choices are reduced to a single dimension in each period: by voting on a pension contribution rate $\tau_{t}$, all the other features of the system at date $t$ are determined. The equilibrium of the voting game is sustained by stationary strategy profiles as in section 4 , with the median voter (in age but also in education) choosing the equilibrium value of $\tau_{t}$ in each period.

The methodology used to investigate the effects of ageing is twofold. First, the author assumes that each economy is initially at steady state at the starting point of the simulations (around the year 2000), and calibrates the model parameters to target the key variables of the economy then (such as the dependency ratio, pension contribution rate, labor force participation, capital-output ratio). In a second step, the author then feeds the model with forecasted values of the relevant economic and demographic variables (among which labor productivity growth, population growth and median voter age) for the year 2050. The output of the simulations is, for each country and for two different effective retirement ages in 2050 (either unchanged with respect to 2000 or increased to 65 years old), an equilibrium pension contribution rate (which is voted upon) and the corresponding replacement rate.

In the words of the author of the study himself, "these simulations give a gloomy picture of the future of social security: under the political constraints imposed by a graying electorate, pension expenditure is forecasted to increase in all countries" (op. cit., p. 207). In Germany, Italy and Spain, the (sometimes massive) increase in contribution rates is however not enough to yield higher replacement rates absent any increase in the effective retirement age, due to the extent of ageing happening in these countries. Higher replacement rates are achieved in all countries only when the effective retirement age is postponed to 65 . Yet, even in this case, most countries see Galasso [2006] presents, among other things, an updated version of the simulations performed in Galasso and Profeta [2004], which is why we do not report Galasso and Profeta [2004]'s results here. 
an increase of their contribution rate over the 50-year time span of the simulations, albeit less stark than if the effective retirement age is left untouched. Indeed, for instance, Galasso [2006] computes that postponing the retirement age in Italy or France from 58 (the effective age in both countries at the time of the study) to 65 years would limit the increase in the contribution rate by 11 and $12 \%$, respectively. In Italy, this would even be enough to allow the contribution rate to decrease from $38 \%$ to $35,5 \%$, instead of increasing to $46,3 \%$ if the retirement age was kept untouched.

Interestingly, as the model incorporates savings and capital, the composition of retiree income between private and public pension plans can be computed: it is forecasted that future retirees will rely more on public pension programs than before, probably given to the fact that they are able to extract more resource from the working generations under the new circumstances.

\subsubsection{Political sustainability with endogenous retirement age}

Galasso [2006] also tackles the next question that comes to mind: ${ }^{33}$ since raising the retirement age is the only way to prevent contribution rate hikes from being massive and replacement rates from decreasing sharply, is there a political majority to raise this retirement age in the concerned countries? To answer this question, the author extends the model discussed in the previous section to allow individuals to vote both on the contribution rate and the retirement age. Given that the multidimensionality of the policy space may be troublesome for the existence of a Condorcet winner, the author models the voting process as an issue-by-issue simultaneous voting game, which yields as output of the model a structure-induced political equilibrium (see Shepsle [1979]).

Under this setup, it is clear that the age profile of preferences for the retirement age will be similar to the one studied in section 3, holding the contribution rate fixed. Besides, if the agents are faced with a higher contribution rate, the opportunity cost of retiring will be lower, meaning older agents will vote for a lower retirement age, all else being equal. The author mentions, however, that since "social security is a dominated asset, a higher contribution rate reduces the overall income of the

\footnotetext{
${ }^{33}$ Galasso [2008] essentially presents the same model and results, and has already been discussed from a theoretical point of view in subsection 3.2.2, to which we refer the reader.
} 
young, hence inducing them to postpone retirement" (op. cit., p. 215). Moreover, population ageing will affect the preferences for the retirement age in the same way as described in subsection 3.2.2: the retirement age $R$ voted in equilibrium will then inevitably rise.

Quantitatively, the simulations feature rises in the effective retirement age that match almost one-to-one the projected rises in the age of the median voter over the contribution rate dimension. Depending on the severity of forecasted ageing, the retirement age is projected to be increased between 5 years (for the USA) and 9 years (for France in Italy) over the study period, thus closing a big part of the initial gap between countries. Notably, the political equilibria in this case feature retirement ages that are systematically above 65 years old, the benchmark used in the previous exercise. This seems to indicate that fears over the sustainability of our pension systems and their capacity to be reformed towards a longer worklife might be overrated. A side effect of this strong increase in retirement age is to mitigate the rise of social security contribution rates (from $9.7 \%$ in 2000 to a forecasted value of $13,5 \%$ in 2050 for the USA, for instance). Concerning the replacement rate, the results are quite contrasted and depend largely on the scope of ageing projected to happen in each country: ${ }^{34}$ while it is forecasted to decrease from $98.9 \%$ to $69.4 \%$ in Italy between 2000 and 2050, it is expected to rise by modest amounts in France (from $55 \%$ to $63.3 \%$ ) and the USA (from $40.8 \%$ to $46.1 \%$ ) over the same time period.

\section{The political impact of ageing on other public pro- grams}

Of course, the most widespread concern linked to ageing is the continuous funding of the generous pension programs that have been set up in the second half of the last century, for all the reasons outlined before. Nonetheless, other public programs may also be at stake due to the way in which they are currently funded (when these programs entail transfers from the young to the old generations), or simply because these public programs are not a priority for a graying electorate. In the following section, we review recent developments in the theoretical and quantitative analysis of

\footnotetext{
${ }^{34}$ Source: Galasso [2008].
} 
the political impact of ageing on these various policies, which range from education to health care, from environment conservation to the composition of taxes falling on labor and capital.

\subsection{Ageing and political support for education}

\subsubsection{Theory}

With education only In the political economy literature, there seems to have been few attempts at studying the impact of demographic structure on education subsidies. Kemnitz [1999] provides an early example of such an attempt. In his 2period OLG model, the size of subsidies to privately purchased education is chosen so as to maximise a weighted sum of the utilities of the two generations (young and old) living in each period. Results are driven by a rather ad-hoc assumption made on these so-called political weights: they are assumed to be an increasing but concave function of the size of each generation. The rationale for introducing such a function is that there may exist larger free-rider problems in bigger groups, when these groups try to organize themselves politically: hidden there is a model of lobbying for public resources. In steady state, it is found that a decline in population growth leads to an increase in education subsidies. When the fertility rate decreases, the decrease in the relative political weight of subsidy recipients is lower than the decrease in their share numbers beacause of the concavity of the political weight function. Since the relative size of the young with respect to the old is itself linked to the tax-price of subsidies, in equilibrium the political costs to the government of subsidizing education fall more than the political gains, and the government is led to increase these subsidies.

Gradstein and Kaganovich [2004] incorporate into a 2-period OLG model two opposing effects of population ageing. On the one hand, ageing increases the proportion of older voters, who cannot reap off the benefits of investing into the productivity of the future workforce. On the other hand, the currently working adults, upon which the current tax falls, can expect to benefit from their investment into future labor productivity through an increase in future PAYG pension payments, and increase interest payments on their savings. Gradstein and Kaganovich [2004] 
find that the second effect dominates in their setup, so that ageing should lead to increased education funding. However, by introducing a version of this same economy with two geographical districts or constituencies, the authors are able to show that constituencies with a (exogenously determined) higher fraction of elderly would be less willing to finance education, at a given time period. The apparent contradiction in these two results is solved if one considers that in the two-district version of the model, education is financed locally, while productivity increases due to education are transmitted to the aggregate level (through perfect capital mobility between the districts). The discrepancy between the costs and benefits of education finance then explains why districts with more old people are more reluctant to finance public education in cross-section, as evidenced by Poterba [1997] (see subsection 7.1.2); however, it also shows that cross-sectional evidence has little external validity when one wishes to investigate the effect of population ageing on education spending at the aggregate level through time.

Levy [2005] brings into the picture the interaction of education policy with general, non-age-related income redistribution. She sets up a model in which agents are not only heterogeneous in terms of age, but also in terms of income. It is shown that, all else being equal (and notably the pre-tax income distribution), a larger young group will lead to decreased education spending, which is crowded out by the untargeted income redistribution.

Joint education and social security Since Rangel [2003] and Boldrin and Montes [2005], the existence of strong linkages between publicly funded education and social security has become obvious, and analysis of these linkages has been extensive since. We believe it is important to understand precisely the nature of these linkages, if one is to be able to make predictions on the impact of ageing on both these programs that constitute a large share of public spending. Common features of the models discussed below ${ }^{35}$ are the necessity of publicly provided education

\footnotetext{
${ }^{35}$ We voluntarily omit from the discussion below papers that do not explicitly tackle the impact of ageing on policy choices, even though these papers have interest on their own in that they help understanding the existing complementarity/competition at the political level between education and pensions; see for instance Poutvaara [2006], Soares [2006] or Kaganovich and Meier [2012]. Additionally, other recent papers (Kaganovich and Zilcha, 2012; Iturbe-Ormaetxe and Valera, 2012), while not focused on exploring the impact of ageing on the size of social security, deliver interesting
} 
to enhance human capital accumulation, and its beneficial impact on future PAYG pensions through the size of the wage bill, but also on fully funded ones through the increase in the return on savings. The papers discussed below share some additional characteristics which are worth emphasizing: they usually feature a working generation, which is taxed to finance the two types of public transfers (education and pensions), and the generations which benefit from them. The policies determined in equilibrium have two dimensions: the amount of resources spent on each program or, equivalently, the tax rate falling on the working generation and a rule to allocate public resources between the two programs. Depending on the model, the political outcome is determined through a vote in which the currently alive generations take part, or results from lobbying from each generation; in case of a vote, the assumption of once-and-for-all voting is usually relaxed, and the two-dimensional nature of the choice to be made sometimes dictates the use of political equilibrium concepts which are alternative to the standard Downsian framework (i.e. assuming probabilistic voting, or using structure-induced equilibria).

Lancia and Russo [2015] offer a good example of the type of arguments that explain the coexistence of the two policy programs under this setup: even if agents vote in each period on the size of both pension programs and there is no reputational effect linked to dismantling social security in a given period, they show that pensioners manage to extract some pensions from the working generation in equilibrium, and that current workers collectively invest in public education because they know this will pay off in the future in the form of higher pensions for themselves. In terms of forecasts of the impact of ageing, these various models typically make a distinction between predictions on the size of each governmental program at the aggregate level, and the actual amounts of transfers which are received by individuals.

To the best of our knowledge, Kemnitz [2000] was the first attempt at formalising the interactions between these two types of intergenerational transfers, and characterising the policy outcome as that of a game between old and active generations. In this paper, the policy decision is made to maximise the support politicians receive from middle-aged workers and old people, this support being a function not

insights into the relationship that exists between the design of social security and political support for public education. 
only of their respective numbers but also on their lobbying activities. Lobbying by individuals of a given generation is costly in terms of their current consumption. While the elderly only favor pensions, the current contributors to the system (i.e. the workers) favor education finance even though no commitment on future pension benefits is possible, since they anticipate they will in turn be in a position to extract these benefits from their children later in the game. In steady state, population ageing is shown to lead to higher per capita income growth: the pension contribution rate increases as a consequence of a decrease in fertility or mortality (through the increased political power of pensioners), which in turn increases the incentives to fund public education to benefit from these higher future pensions. It should be noted, however, that only the amount devoted to education per child is supposed to increase here, but not necessarily the share of national income devoted to education in the case of fertility reduction: education per child might only increase due to the increased effectiveness of public spending. To put it differently, the tax price of spending on education falls when the relative number of children falls, so willingness to fund education increases.

Batté [2015] also aims at studying how demographic changes impact our collective willingness to finance social security and education. Contrary to other papers, the economy is assumed here to be closed, and the impacts of ageing on capital accumulation and the relative prices of the different inputs is taken into account explicitly. Another distinguishing feature, common only with Naito [2012], is the existence of intragenerational heterogeneity. Individual preferences for taxation and spending are aggregated through probabilistic voting. Under the assumption of nonstrategic voting between periods, Batté [2015] derives predictions on the impact of fertility and mortality rate changes on the level and composition of public spending: in particular, population ageing (whatever the cause) points out to a rising tax burden, and thus a bigger size of government. Analytical results fail to unambiguously state which type of policy is likely to be expanded as population ages, but simulations under plausible parameters point out to rising pension and education expenditures as a share of GDP. At the same time, higher expenditures at the level of the whole economy may fail to translate into higher pensions per capita when 
longevity rises.

Gonzalez-Eiras and Niepelt [2007] also study the joint determination of the size of education and pensions, and incorporate the study of capital taxation as well. Their model is calibrated to US data to generate predictions about the effects of fertility decrease and longevity extension on labor supply, labor and capital income taxes, pensions, human and physical capital investment: the ageing of population is found to induce a reallocation of public spending towards excessively large levels of pensions (with a GDP share of retirement benefits going from about 5\% in 2005 to $10 \%$ in 2075 ), at the cost of education spending (with the education spending over GDP ratio going from $6 \%$ to $5 \%$ over the same period of time). This results in the productivity growth of the economy being severely slashed down, due to the endogenous growth component present in their model.

Gonzalez-Eiras and Niepelt [2012] build on a standard two-period OLG model with endogenous growth based on physical and human capital accumulation. Its main contribution is to incorporate retirement age as a policy choice. Individuals are successively modelled as young and old adults, and homogenous in dimensions other than age. The young have to determine their labor supply and their choice of savings; a fraction $\delta$ of the young get to live to the next period, in which they consume their savings but can also work part-time ${ }^{36}$. The share of time spent working while old, denoted $\rho$ (envisioned as a proxy to retirement age policy), is a policy variable as well as $\tau_{e}$ and $\tau_{p}$, the tax rates on labor income used to finance education of the next generation young and the pensions of the current old, respectively. Preferences on those three policy choices are aggregated assuming probabilistic voting. Population ageing is shown to act on policy decisions through different channels. Firstly, population ageing, by increasing the political power of the elderly, tends to raise $\tau_{p}$ but to decrease $\tau_{e}$ and $\rho$ : elderly voters use their bigger political clout to increase the transfers they receive at the expense of productive investment, while trying to reduce their labor force participation. This effect is countered by the fact that the bigger share of elderly in the population makes it more profitable (from a government finance point of view) to raise the retirement age $\rho$, which allows to

\footnotetext{
${ }^{36}$ It is noteworthy that the effect of fertility are also taken into account here, even though the effects of fertility and longevity cannot be analytically disentangled on a two-period OLG structure.
} 
decrease $\tau_{p}$ and increase $\tau_{e}$. Thirdly, increased longevity makes forward investment more profitable for young households, which in turn would tend to increase public investment in education $\tau_{e}$. Finally, and since there are dynamic linkages between policies at successive periods, future anticipated demographic change can lead to deviations in current policy: this implies that permanent demographic change can lead to non-monotone dynamics in policies. Based on this analysis, the authors make quantitative predictions for a stylised aggregate of rich OECD economies: it turns out that projected demographic change over the 2000-2080 period would lead to a modest increase in both $\tau_{p}$ and $\tau_{e}$ (by respectively $2 \%$ and $3 \%$ of taxable labor income), with a larger increase in $\rho$ corresponding to a 6 -year increase in the retirement age (to be put into perspective with the expected 8-year increase in life expectancy over the same period). However, if one shuts down the retirement age adjustment mechanism, the contribution rate for pensions would sharply increase in equilibrium, while the tax rate to finance education would barely decrease over the 2000-2080 time range. Taking into account the possibility to enact changes in the retirement age thus leads to important insights on the future evolution of retirement and education policies, as already outlined in section 3 .

Ono [2015] also formulates a three-period OLG model where public education funding and social security coexist as the outcome of a political process. Key distinguishing features are the existence of altruism towards children, and the possibility to invest privately in education (on top of standardized, public education). The model sheds light on the key role of longevity (proxied as usual by an exogenous survival probability into old age $\delta$ ) as a determinant of these two types of spending. Depending on the relative efficiency of private versus public education, two political equilibria may coexist, one featuring only private education with public spending focusing exclusively on pensions, while the other one is distinguished by no private education spending and positive public spending on education (along with pensions). Population ageing (an increase in $\delta$ in this setting) induces several effects, which may or may not exist depending on the equilibrium selected: ${ }^{37}$ firstly, greater longevity implies middle individuals attach more weight to their offsprings' acquisi-

\footnotetext{
${ }^{37}$ Note that the author remains silent on equilibrium selection. Multiplicity of equilibria is only explored to rank policies in terms of human capital accumulation and welfare.
} 
tion of human capital, implying an increased incentive to invest in private education. Secondly, an increase in the number of pensioners has the direct political effect of increasing their weight in the political process, hence a tendency to increase pensions at the expense of both types of human capital accumulation. Thirdly, higher survival probability into old age means middle-aged individuals have a greater incentive to enact public education funding for their children, whose human capital they have a higher chance of enjoying later in life.

Naito [2012] elaborates on the political linkages between public education and pensions, by setting up a tractable model in which the level of inequality in initial human capital endowments plays a role on the comparative statics with respect to demography. It considers a canonical three-overlapping-generation economy with exogenous and constant fertility rate $n$, but without mortality. The assumptions on production technology and openness of the economy are such that human capital accumulation is the only source of growth, and provides the only dynamic linkage between policies at different periods. For each individual, human capital is produced using parental human capital and public education. The only policy subject to a vote is the total labor income tax rate $\tau$ : the share of tax receipts that goes to education and pensions is assumed to be fixed from the outset. The conflict about policy is here both inter- and intragenerational: as individuals of a same generation differ in their human capital, and since both types of policies redistribute income intragenerationally, the policy outcome reflects the interests of a coalition of poor active workers and retirees against the higher-endowed workers. The author restricts his attention to a subclass of stationary, fully forward-looking Markov equilibria with a constant tax rate $\tau$ over time. Interestingly, a rise in the fertility rate $n$ has two opposite effects on the equilibrium tax rate: on the one hand, for a given decisive voter, a rise in $n$ decreases the optimal funding rate for education (mainly because education expenditures have to be shared among more people). On the other hand, when $n$ increases, the old generation loses weight so that the willingness to fund education expenditures increases; this latter effect is shown to be stronger when inequality in human capital is higher. As a whole, it is shown that because of these various political effects, human capital accumulation rate increases with $n$ for 
high levels of initial inequality, while it decreases when $n$ increases for low levels of inequality.

\subsubsection{Empirical evidence}

Empirics with education only: Miller [1996] performs a panel estimation of the impact of the population structure on educational spending for U.S. states. She explicitly tests for interest-group determination of spending, by including as explanatory variables the proportion of parents of school-age children, and of retirees, in the electorate. The dependent variable is the log of real per adult expenditures on education (state and local) for the years 1960, 1970, 1980 and 1990. While most specifications show a positive effect of the proportion of parents on spending, elderly proportion seems insignificant. A similar analysis on Texas counties, conducted for the years 1970 and 1980, finds both variables to be significant with the expected sign, however.

Poterba [1997] similarly uses panel data on K-12 education spending on the U.S. states, over the 1960-1990 period, using (log of) education spending per child as the dependent variable. The proposed explanatory variables this time include the proportion of school-aged children and elderly in the state population of each state. It is estimated that per-child spending has an elasticity with respect to the over-65 population share of approximately -0.25: in other terms, "a one standard deviation change in the share of elderly in the population, a shift from 0.108 to 0.130 , results in almost a 5\% decline in per-pupil education spending", which is sizeable. This also needs to be put into perspective with the fact that other governmental programs are rising with the share of the elderly in the population. On the other hand, per capita education spending has a negative elasticity (varying between -0.4 and -1.0) with respect to the fraction of school-age children in the population. While this result may seem surprising, the author emphasizes that other types of public spending are more negatively affected by increases in the share of the young: thus, the share of public spending that goes to the young increases when the share of the young in the population increases. Fernandez and Rogerson [1997] perform a similar analysis on U.S. states from 1950 to 1990. In their main specification, the logarithm of schooling 
expenditures per student is regressed on the log of income per capita, the fraction of the population of school age and the fraction of the adult population over 65 . While the coefficient on the share of students is insignificant, the one on the share of elderly is consistently negative and significant (around -0.2). On the other hand, per student education expenditures go hand in hand with income per capita.

Ladd and Murray [2001] explicitly build onto the approach in Poterba [1997], while shifting the unit of observation away from states to local counties. They start by presenting descriptive evidence showing that elderly residential choices may be related to the level of spending on education by the county. In order to try to eliminate the bias created by this Tiebout sorting of elderly with respect to local taxes, they then proceed to estimating a panel equation where the share of the elderly in a county is instrumented by the same share in previous census. By so doing, Ladd and Murray [2001] obtain a significantly smaller estimate of the elasticity of educational spending with respect to the share of pupils; more importantly, the share of the elderly now becomes statistically insignificant, suggesting that elderly actually do not exert any downward pressure on spending per child.

Harris et al. [2001] use panel data on spending and demographic structure at the school district level to reconcile the findings in Poterba [1997] and Ladd and Murray [2001]. Indeed, they show that the elderly are much less likely to support state funding than funding at the local, school-district level. This, the authors remark, is consistent with the widely accepted observation that the quality of local schools is capitalised in housing values.

Grob and Wolter [2007] perform a panel analysis of spending on compulsory education for Swiss Cantons, between 1990 and 2002. It shows that under a Canton fixed-effect specification, the percentage of retired in the population has a negative, yet significant at the $10 \%$ level only, effect on educational spending per child. Using first differences, the authors find that variations in the number of pupils (resp. the number of retirees) have a positive (resp. negative) impact on total education spending.

Empirics with several public programs: Borge and Rattso [2008] use a specification very similar to that of Poterba [1997], to evaluate the impact of population 
structure on three welfare programs of the 275 Danish local governments, over the 1989-1996 period. The welfare programs considered are child care, compulsory education and elderly (instituionalized) care. The demographic variables are the fraction of the potential recipients of each of the three programs (i.e. resp. the 0-6 years, 7-15 and 80+ age groups) over the total population. Using as dependent variables the spending per capita on each program, the authors first find that being part of a large age cohort is a disadvantage in terms of transfers received. They also shed into light that while the elderly exert significant crowding out on spending towards the younger generations, the opposite is not true.

Surveys of voter preferences All the aforementioned papers attempt to analyse the empirical impact of the age structure of the population on the size of these public programs, which is the outcome of the political process concerning them. Meanwhile, a complementary approach has been developed by some other papers (Brunner and Balsdon [2004], Berkman and Plutzer [2004], Cattaneo and Wolter [2009], Busemeyer et al. [2009], Sorensen [2013]) that have used individual surveys about the likelihood to vote for specific, age-related transfer policies, in order to analyse the role of age on the individual preferences on these policies. For instance, Cattaneo and Wolter [2009] use a representative survey of Swiss voters to show the elderly are less likely to be willing to fund education programs, and prefer spending on health and social security. They find that these result still hold after controlling for the fact that the elderly are less supportive of public spending in general. The interest of this type of analysis is to establish a possible causal link between the age structure of the population and the policy outcome that goes through individual preferences, and not only through the tax cost of spending on the different programs as the age structure varies.

\subsection{Ageing and support for health care}

Surprisingly enough, the recent political economy literature contains few articles linking the ageing of the electorate and the evolution of public health care provision, even though it may be considered as hot a topic as pensions. We will focus here on only one significant contribution, although other recent papers on the political 
economy of health care without direct focus on ageing may be worth mentioning here, such as Moreno-Ternero and Roemer [2007] or De Donder and Hindriks [2007]: indeed, the results and insights obtained can be extended to a situation with a changing composition of the population with regards to ageing.

Bethencourt and Galasso [2008] emphasise a political complementarity between two transfer programs, namely pensions and public health care. It is known for some time already (Philipson and Becker [1998]) that the existence of pensions as annuity encourages investment in healthcare. Here, expenditure in health care reduces the longevity differential between rich and poor individuals, thereby making pensions more attractive for the poor individuals with lower longevity. The authors support their analysis by pointing out the existence of a health gradient in income and the fact that publicly provided healthcare increases more longevity for the low-income than for the high-income individuals (in other words, the health production function is concave). Essential to the establishment of a political equilibrium supporting a large welfare system is the intragenerational redistribution element of both programs. Their model features a 2-period OLG endowment economy where young agents do not take any economic decisions (they only participate in the vote over social security and healthcare). Old agents (who are heterogeneous in the endowment they received) use their income to finance private healthcare and non-health expenditures. They are taxed linearly to finance non-contributory pensions and public healthcare. Only public healthcare raises the life expectancy, which is modeled as the fraction of the second period during which agents will enjoy their pension payments. On the political side of the model, the authors assume that a majoritarian vote takes place over the size and composition of the welfare state. They use subgame perfect structure-induced equilibrium to reduce the game to a (degenerately) dynamic, issue-by-issue voting game. Under adequate parameter restrictions, an equilibrium with positive taxation is supported by a coalition of the old and the young poor, provided the amount devoted to healthcare is sufficient to increase the young poor life expectancy up to the point where they support pensions. Concerning the determination of the composition of the system, the authors find that the preferred policy mix depends solely on income. For any transfer size, richer agents prefer a purely 
pension-based system, since it is the one which provides the widest longevity gap in income and thus redistributes income the least. As agents become poorer, they prefer a bigger part of the welfare system to be spent on healthcare, in order to make receiving pensions more worthwhile. The authors also find out that an increase in health care technology leads to a larger welfare state and a larger pension share. Using a calibrated version of the model for the U.S. economy in the early 80 s, they find that such a technology improvement would then cause an increase in ageing, and also higher per-capita welfare spending. An interesting potential development of this line of research would be to analyze the impact of a change in fertility, which enters the model here as an exogenous parameter.

\subsection{Ageing and long-term care}

Long-term care can be broadly defined as the supply of help to elderly, dependent people, regarding basic daily activities such as eating, dressing, bathing... It can be extended to include help to perform activities that are instrumental to day-to-day life like cooking, cleaning, taking medication or going to places which are further than walking distance. The risk of long-term care (hereafter LTC) needs showing up at the individual level strongly increases around the age of 80 years old. As it turns out, the " 80 years and above" category is the fastest growing segment of population in many ageing, industrialised societies. It is then no wonder that the number of dependent elderly, and the cost of providing for their LTC, are expected to increase dramatically over the coming years: according to European Commission [2015], the baseline scenario ${ }^{38}$ for the future evolution of LTC expenditures in the European Union implies a hike of public outlays from 1.6\% of GDP in 2015 to $4.1 \%$ in 2060, if coverage rates and cost per dependent remain the same throughout the period.

An important issue concerns the provision of LTC: in many countries, the bulk of LTC is still provided informally by family members, a feature which may change in the future due to evolutions of family structure or female labor force participation. Formal care can also be provided by the state or the market: it should be noted, however, that the market for LTC (and especially LTC insurance) is cur-

\footnotetext{
${ }^{38}$ The scenario mentioned here assumes that half of future gains in life expectancy will be spent in good health, and half in disability.
} 
rently quite thin, as evidenced by Brown and Finkelstein [2011] and Pestieau and Ponthière [2011]. The question of our collective willingness to fund public provision of LTC is thus a pressing issue, which has received some increased attention in the recent literature: indeed, most recent papers on the political economy of LTC are devoted to finding the reasons why public financing of LTC remains underdeveloped in many countries. A pervasive argument (Nuscheler and Roeder 2013;De Donder and Pestieau [2016];De Donder and Leroux, 2015) is the crowding-out of social financing of LTC by direct care provision or purchase, be it through financial transfers from the family, depletion of the concerned individual's own savings, or informal care from relatives. Another line of explanation [De Donder and Leroux, 2013] stresses out the fact that agents may be myopic when making decisions regarding LTC, in the sense that they underestimate their probability to become dependent in old age: this argument tends to explain both the low level of market coverage and the low political demand for a publicly funded system.

Nuscheler and Roeder [2013] and De Donder and Pestieau [2016] both consider setups in which agents differ in income and LTC needs, even though they adopt a different perspective in terms of the realization of LTC needs. In Nuscheler and Roeder [2013], dependence risk is already realized, so that families either have to support a dependent parent or they do not. The political conflict then pits families with healthy parents against families with a sick parent, but also poor families against rich families, since a vote also occurs on the level of income redistribution. In this setup, the impact of ageing on the level of public LTC financing is ambiguous, and depends on the tax elasticity of the supply of informal care. Indeed, population ageing is shown in the model to make the income tax more distortionary, so that income taxation is lower at the political equilibrium; as a result, the opportunity cost of giving informal care to one's parent (instead of participating to the labor market) increases, which decreases the supply of informal care in equilibrium. If informal care decreases sufficiently, then agents may ask for public financing of LTC to step in.

On the opposite, De Donder and Pestieau [2016] adopt an ex ante perspective, in which agents rather differ in the probability to become dependent (as well as the 
probability to get family help and the extent of that help). The only policy chosen at the political equilibrium is here the income tax rate, where all the income tax is used to fund social LTC insurance. In this setting, the interaction between family help, market insurance and social insurance is fairly complex: however, agents are shown to prefer social insurance to market insurance if they have a relatively low level of income or a relatively high level of risk of being dependent, ceteris paribus, which is due to the fact that social insurance redistributes across income and risk levels while private insurance is actuarially fair. Besides, good prospects of family help (i.e. a high probability to receive help from the family and/or a high level of help) reduce demand for any kind of insurance, all else being equal, as expected. In this context, ageing (which can be represented by a higher probability to become dependent) unambiguously increases the need for total LTC provision: however, the effect on social LTC insurance is ambiguous, given that its return can be shown to decrease with the average probability to become dependent at the scale of the entire population.

\subsection{Ageing and the environment}

Although some may consider the subject of environment conservation very loosely related with our subject, we argue that its characteristics make it a subject with important intergenerational dimensions. Indeed, to use the terminology introduced by Rangel [2003], a healthy environment can be considered a "forward intergenerational good" in the sense that it is financed by a given generation to be consumed mainly by the next one (as opposed to "backward intergenerational goods" like pensions for instance), especially if one considers climate change. In this sense, the way in which a society decides on the funds to allow for environment conservation may well be impacted by the age structure of its population as well.

Ono [2005] is, to the best of our knowledge, the first significant contribution on this topic. It focuses on the impact of greater longevity and lower growth rate of population may affect the level of a politically-determined environmental tax, and through it the quality of environment over time.

This paper uses a two-period OLG model with environmental quality and un- 
certain lifetimes. Lifetime uncertainty is represented by an exogenous probability $\delta$ to survive into old age. It is assumed this uncertainty cannot be completely hedged against in the savings decision of young agents, as they can only save a fixed fraction $\gamma$ of their savings in the form of annuities. On the production side, it is assumed that firms create environmentally harmful emissions as by-products, in the form of a fixed fraction $\eta_{y}$ of the output of the firms. To repair the damage made by emissions, an environmental tax $\tau$ on each unit of production is levied in each period. The proceeds of the tax are used to improve environmental quality, which is modeled as a stock that depletes with emissions and is maintained by tax receipts. Finally, agents care about consumption and environmental quality when old, in a separable fashion. The political process boils down to a short-lived representative government that sets up $\tau_{t}$ in each period, so as to maximise a weighted sum of the utilities of currently living generations: representatives are assumed to have rational expectations about future policies, but to act in a myopic fashion with regards to the impact of current decisions on future ones. A first insight from the model is that longevity has no impact on the level of the environmental tax at steady state, while a slower level of population growth $n$ will reduce the level of the tax. However, the final impact on environmental quality is more complex. Indeed, increased longevity leads to a lower level of environmental quality under partial annuitization of savings, while having no effect at all in the case of full annuitization. On the other hand, environmental quality increases when the rate of population growth decreases: indeed, a lower $n$ enhances capital accumulation, in a way that increases environmental investment more than emissions for a given level of $\tau$. This effect outweighs the negative effect of $n$ on $\tau$ described above, hence the result. As is already the case for pensions, it is worth stressing that in this case too, one needs to take into account the effect of population change on capital accumulation decisions as well as their more politically proximate effects, if one is to get a full understanding of the consequences of political ageing.

\subsection{Capital vs. labor taxes}

Bassetto [2008] studies a setup slightly more complex than an OLG model with 
pensions, including capital taxes (that fall on the old) along with labor taxes (falling on the young), and tax proceeds that can be used to finance a public good and lump-sum transfers to either generation (or both). The argument for looking at this broader picture comes from generational accounting: changing demographics will probably affect what each generation pays to the system, thereby possibly offsetting the changes in what they receive as a consequence of the demographic shock. An interesting feature of the model used in this paper is the modeling of the political process as a bargaining game. In each period, citizens are drawn randomly to make proposals that have to be accepted unanimously to be implemented, with a small probability that the game terminates with a government shutdown for the period each time a proposal is rebuked. In this environment, each generation holds a veto power over the decisions, such that the outcome must somehow balance the gross contributions from and transfers to both the old and young. Moreover, concerning the public good financing, it can be seen that if a generation values less the good than the other one, this generation benefits from hold-up power (here, the threat of a shutdown), which it may use to extract larger transfers. Under a setup where the young only supply labor and the old only capital to the production process, the author points out that the young will be willing to reduce the size of both their contribution and the transfers they receive (since the labor tax base is sensitive to the tax rate), while the old will accept large contributions in exchange for big transfers (as the capital tax base is predetermined by past decision and is thus insensitive to the tax rate chosen). Let us now convey the intuition of the consequences of population ageing, under the assumption that young people value more the public good than the old ${ }^{39}$ : in this case, as the old agents become relatively more numerous, their decision power increases and is used to decrease the overall size of the government, and in particular decrease public good financing. Moreover, and even though they manage to negotiate higher overall transfers from the young, this is not enough to counteract the fact that transfers have to be shared between more old people, so that the per capita transfer they get will decrease. This effect on the transfer side needs to be added to the fact that the capital tax rate also increases,

\footnotetext{
${ }^{39}$ This would be the case, the author argues, if the public good is itself somehow a forward intergenerational good, like environmental quality (see subsection 7.4).
} 
so that the overall net transfer per capita to the old is further degraded. From the point of view of the young, ageing leads to increased labor tax rate and increased net contributions per capita, on top of the reduction in public good consumption, so the overall effect is unambiguously negative for them. On top of this comparative statics on the steady state of the economy, the author conducts two comparative dynamics exercises to explore what happens to these taxes and transfers when a demographic shock hits, whether anticipated or unanticipated. It is shown that the output of the model is consistent with the historical experience if one considers an anticipated ageing shock at the time of the baby boomers generation, with transfers to the old going upwards when this generation is active (i.e. young), before an eventual contraction.

Contrary to the intuitions conveyed by the preceding paper, Mateos-Planas [2010] sets up a general-equilibrium model to predict a link between ageing and increased capital taxation, in a model where both labor and capital can be taxed. For the prediction to hold, the young need to hold less capital than the old, which appears reasonable, and the ageing process needs to be large enough to shift the identity of the median voter to induce a movement of the tax rate in equilibrium.

\section{Conclusion}

Summary of previous sections In the previous sections, we have thus given an account of the recent literature on the political economy of pensions, and more precisely how population ageing is compelling electoral democracies to rethink collectively the size and design of their pension systems. A first, and essential step according to us, was to remind the reader why public PAYG pensions were supported by a majority of the electorate in the first place: arguments of reduced time horizon of the median voter, or the existence of a within-cohort redistribution component in PAYG pension schemes, are the most compelling reasons why these programs exist in the first place. Once this theoretical framework for the political sustainability of pensions has been established, we have been able to give an account on the impact of ageing on the size of the programs. The effects at play are slightly different depending on whether population ageing is caused by fertility decreases 
or life expectancy increases: in any case, they fall into two categories. The political effect of ageing is unambiguous: as population ages, the weight of old voters in the electorate increases, which will give incentives to politicians seeking votes to propose electoral platforms with more generous retirement packages. What we call the economic effect of ageing is less clear cut, but essentially hinges on how the internal return of the PAYG system is modified as the age structure of the economy changes. The theoretical literature essentially associates higher life expectancy to higher sizes of pension programs, while lower fertility yields more ambiguous results. Empirical evidence suggests that measures of population ageing such as the old-age dependency ratio can be estimated to cause higher pension spending. Considering other public programs alongside pensions does not seem to modify the broad sense of this result: it adds to the previous analysis the finding that education funding is generally at risk with a graying electorate.

This chapter has also studied the impact of ageing on the retirement age: to sum up, ageing acts as a negative shock on the return of the PAYG pension system. Then, agents faced with ageing suffer a negative income shock, which will result in their optimal retirement age being higher than before (retirement, or leisure, being a normal good). Therefore, ageing is predicted to induce the electorate to choose a higher retirement age.

The way forward As stated in subsection 7.2, further research is warranted on the political economy of health care and long-term care, especially since recent increases in life expectancy make the financing of these governmental program an ever more pressing issue.

As shown in Galasso [2006], work on the joint political determination of the size of the pension system and the retirement age seems a promising avenue of research. Galasso and Profeta [2004] also suggest that the importance of family ties (and hence altruism considerations) should be taken into consideration, if one is to make sense of the political decisions taken by individuals as regards the pension system. Indeed, they indicate that countries with relatively more frequent multi-generational living arrangements would tend to choose larger pension systems, as adult children living with their parents are more likely to be in favor of pensions than their alone-living 
counterparts for intra-household transfer reasons. It can be argued that this effect is sizable, especially when comparing countries: in Southern Europe or Japan, a high fraction of elderly individuals (around $40 \%$ or more) live with their adult children, compared with just less than $15 \%$ in the US. ${ }^{40}$

Another overlooked characteristic of pension systems is its intragenerational redistribution component. Galasso and Profeta [2004] recall the distinction between Beveridgian and Bismarckian pension systems, the former aiming at giving a base income at retirement independently from past contributions, while the latter tends to provide equal replacement rates for all individuals. Indeed, recent reforms go in the direction of extended coverage and increased minimum pensions to fight poverty among elders, while at the same time tightening the eligibility criteria and containing the increases in spending by tinkering with benefits formula for the general population. It therefore appears worthwhile to ask the question whether most pension systems are not becoming increasingly Beveridgian (or at least progressive in some dimensions), as well as to investigate the political reasons behind this institutional evolution.

We would also like to add that further theoretical work should consider including the possibility for the electorate to choose to run some deficits on its pension system: indeed, most theoretical papers assume from the outset that the electorate determines the size of a system by merely setting the contribution rate on labor income, the value of pension benefits being merely set so that the pension system budget is in equilibrium at all times. Such formulations have several drawbacks, the most important one being that pension systems are never exactly in budgetary equilibrium for any fiscal year. It also significantly blurs the distinction between defined-benefit and defined-contribution systems. It would probably be a hard process, as there would be several decision dimensions (including the size of the system and its degree of financing by current contributions) to consider, and would most likely require precious insights from the political economy literature on inaction and reform delay, and debt (see Drazen [2000], chapters 3 and 10, but also Tepe and Vanhuysse [2012] for the point of view of political science). More generally, every step should be made

\footnotetext{
${ }^{40}$ Source:Howe and Jackson [2003], as cited in Galasso and Profeta [2004].
} 
in terms of modelling or quantitatively assessing the future evolutions of the pension systems to better explain the institutional details of these systems, and how these are likely to be impacted by the coming demographic shockwave. 


\section{References}

Henry Aaron. The social insurance paradox. Canadian Journal of Economics and Political Science, 32:371-74, 1966.

Andrew B. Abel, N. Gregory Mankiw, Lawrence H. Summers, and Richard J. Zeckhauser. Assessing dynamic efficiency: Theory and evidence. The Review of Economic Studies, 56(1):1-19, January 1989. ISSN 00346527.

Marco Bassetto. Political economy of taxation in an overlapping-generations economy. Review of Economic Dynamics, 11(1):18-43, Jan 2008.

Loïc Batté. Demography and intergenerational public transfers: a political economy approach. Mimeo, January 2015.

Michael B. Berkman and Eric Plutzer. Gray peril or loyal support? the effects of the elderly on educational expenditures*. Social Science Quarterly, 85(5):1178-1192, Dec 2004

Carlos Bethencourt and Vincenzo Galasso. Political complements in the welfare state: Health care and social security. Journal of Public Economics, 92(3-4): 609-632, April 2008.

Duncan Black. On the rationale of group decision-making. Journal of Political Economy, 56(1):23-34, February 1948.

S. Blondal and S. Scarpetta. The retirement decision in oecd countries. Technical Report AWP 1.4, OECD, 1998.

D. E. Bloom, D. Canning, and G. Fink. Implications of population ageing for economic growth. Oxford Review of Economic Policy, 26(4):583-612, Dec 2010. ISSN 1460-2121.

Robin W. Boadway and David E. Wildasin. A median voter model of social security. International Economic Review, 30(2):307-328, May 1989. 
Henning Bohn. Social Security and Demographic Uncertainty: The Risk-Sharing Properties of Alternative Policies, pages 203-246. University of Chicago Press, January 2001.

M. Boldrin and A. Rustichini. Political equilibria with social security. Review of Economic Dynamics, 3(1):41-78, 2000.

Michele Boldrin and Ana Montes. The intergenerational state education and pensions. Review of Economic Studies, 72(3):651-664, 072005.

A. Bommier, T. Magnac, B. Rapoport, and M. Roger. Droit à la retraite et mortalité différentielle. Economie et Prévision, 168:1-16, 2006.

Rainald Borck. On the choice of public pensions when income and life expectancy are correlated. Journal of Public Economic Theory, 9(4):711-725, 2007.

Lars-Erik Borge and Jorn Rattso. Young and old competing for public welfare services. CESifo Working Paper Series 2223, CESifo Group Munich, 2008.

Friedrich Breyer. On the intergenerational pareto efficiency of pay-as-you-go financed pension systems. Journal of institutional and theoretical economics, 145:643-58, 1989.

Friedrich Breyer. Voting on social security when labor supply is endogenous. Economics \& Politics, 6(2):119-130, 1994a. ISSN 1468-0343.

Friedrich Breyer. The political economy of intergenerational redistribution. European Journal of Political Economy, 10(1):61 - 84, 1994b. ISSN 0176-2680.

Friedrich Breyer and Ben Craig. Voting on social security: Evidence from oecd countries. European Journal of Political Economy, 13(4):705-724, December 1997.

Friedrich Breyer and Martin Straub. Welfare effects of unfunded pension systems when labor supply is endogenous. Journal of Public Economics, 50(1):77-91, January 1993.

Jeffrey R. Brown and Amy Finkelstein. Insuring long-term care in the united states. Journal of Economic Perspectives, 25(4):119-42, Fall 2011. 
Edgar K Browning. Why the social insurance budget is too large in a democracy. Economic Inquiry, 13(3):373-88, September 1975.

Eric Brunner and Ed Balsdon. Intergenerational conflict and the political economy of school spending. Journal of Urban Economics, 56(2):369-388, Sep 2004.

John Bryant. Modelling the effect of population ageing on government social expenditures. Treasury Working Paper Series 03/15, New Zealand Treasury, March 2003.

Marius R. Busemeyer, Achim Goerres, and Simon Weschle. Attitudes towards redistributive spending in an era of demographic ageing : the rival pressures from age and income in 14 oecd countries. Journal of European Social Policy, 19(3): 195-212, 2009.

Georges Casamatta, Helmuth Cremer, and Pierre Pestieau. The political economy of social security. The Scandinavian Journal of Economics, 102(3):503-522, 2000.

Georges Casamatta, Helmuth Cremer, and Pierre Pestieau. Voting on pensions with endogenous retirement age. International Tax and Public Finance, 12(1): 7-28, January 2005.

Georges Casamatta, Helmuth Cremer, and Pierre Pestieau. Is there a political support for the double burden on prolonged activity? Economics of Governance, 7(2):143-154, May 2006.

M. Alejandra Cattaneo and Stefan C. Wolter. Are the elderly a threat to educational expenditures? European Journal of Political Economy, 25(2):225-236, Jun 2009.

J. Ignacio Conde-Ruiz, Vincenzo Galasso, and Paola Profeta. The role of income effects in early retirement. Journal of Public Economic Theory, 15(3):477-505, 2013.

J.Ignacio Conde-Ruiz and Vincenzo Galasso. Early retirement. Review of Economic Dynamics, 6(1):12-36, jan 2003.

J.Ignacio Conde-Ruiz and Vincenzo Galasso. The macroeconomics of early retirement. Journal of Public Economics, 88(9-10):1849-1869, August 2004. 
Juan C. Conesa and Carlos Garriga. Optimal fiscal policy in the design of social security reforms. International Economic Review, 49(1):291-318, February 2008.

Juan C. Conesa and Dirk Krueger. Social security reform with heterogeneous agents. Review of Economic Dynamics, 2(4):757-795, October 1999.

Juan Carlos Conesa and Carlos Garriga. Optimal response to a transitory demographic shock in social security financing. Federal Reserve Bank of St. Louis Review, 33-48(Jan):33-48, 2009.

Thomas F. Cooley and Jorge Soares. A positive theory of social security based on reputation. Journal of Political Economy, 107(1):135-160, February 1999.

J.L. Coronado, D. Fullerton, and T. Glass. The progressivity of social security. Working Paper 7520, NBER, 2000.

Vincent P. Crawford and David M. Lilien. Social security and the retirement decision. The Quarterly Journal of Economics, 96(3):505-529, August 1981.

Helmuth Cremer and Philippe De Donder. Life expectancy heterogeneity and the political support for collective annuities. The Scandinavian Journal of Economics, pages $n / a-n / a, 2016$. ISSN 1467-9442.

Helmuth Cremer, Philippe De Donder, Dario Maldonado, and Pierre Pestieau. Voting over type and generosity of a pension system when some individuals are myopic. Journal of Public Economics, 91:2041-2061, 2007.

Philippe De Donder and Jean Hindriks. Voting over social security with uncertain lifetimes, pages 201-220. Kluwer Academic Publishers, 2002.

Philippe De Donder and Jean Hindriks. Equilibrium social insurance with policymotivated parties. European Journal of Political Economy, 23(3):624-640, September 2007.

Philippe De Donder and Marie-Louise Leroux. Behavioral Biases and Long-Term Care Insurance: A Political Economy Approach. The B.E. Journal of Economic Analysis $\&$ Policy, 14(2):551-575, May 2013. 
Philippe De Donder and Marie-Louise Leroux. The political choice of social long term care transfers when family gives time and money. CESifo Working Paper Series 5384, CESifo Group Munich, 2015.

Philippe De Donder and Pierre Pestieau. Private, social and self-insurance for longterm care in the presence of family help. Journal of Public Economic Theory, 2016.

Grégory de Walque. Voting on Pensions: A Survey. Journal of Economic Surveys, 19(2):181-209, 042005.

Peter A. Diamond. National debt in a neoclassical growth model. The American Economic Review, 55(5):1126-1150, December 1965.

Peter A. Diamond. A framework for social security analysis. The American Economic Review, 8:275-298, June 1977.

Richard Disney. Population ageing and the size of the welfare state: Is there a puzzle to explain? European Journal of Political Economy, 23(2):542-553, June 2007.

A. Drazen. Political Economy in Macroeconomics. Princeton University Press, 2000.

Dick Durevall and Magnus Henrekson. The futile quest for a grand explanation of long-run government expenditure. Journal of Public Economics, 95(7-8):708-722, August 2011.

Dennis Epple and Richard E. Romano. Public provision of private goods. Journal of Political Economy, 104(1):57-84, February 1996.

European Commission. Progress and key challenges in the delivery of adequate and sustainable pensions in europe (a joint report on pensions). Occasional Papers 71, European Commission, Directorate-General for Economic and Financiall Affairs, November 2010 .

European Commission. The 2015 ageing report: Economic and budget projections for the 28 member states (2013-2060). Technical report, European Commission, Directorate-General for Economic and Financiall Affairs, April 2015. 
Raquel Fernandez and Richard Rogerson. The determinants of public education expenditures: Evidence from the states, 1950-1990. Working Papers 97-16, C.V. Starr Center for Applied Economics, New York University, 1997.

Lorenzo Forni. Social security as markov equilibrium in olg models. Review of Economic Dynamics, 8(1):178-194, January 2005.

Drew Fudenberg and Jean Tirole. Game Theory, volume 1 of MIT Press Books. The MIT Press, 1991.

Vincenzo Galasso. The Political Future of Social Security in Aging Societies. MIT Press Books. The MIT Press, 2006.

Vincenzo Galasso. Postponing retirement: the political effect of aging. Journal of Public Economics, 92(10-11):2157-2169, October 2008.

Vincenzo Galasso and Paola Profeta. The political economy of social security: a survey. European Journal of Political Economy, 18(1):1-29, March 2002.

Vincenzo Galasso and Paola Profeta. Lessons for an aging society: the political sustainability of social security systems. Economic Policy, 19:63-115, 2004.

Vincenzo Galasso and Paola Profeta. How does ageing affect the welfare state? European Journal of Political Economy, 23:554-63, 2007.

François Geerolf. Reassessing dynamic efficiency. Working paper, 2013.

Jack A. Goldstone, Eric P. Kaufmann, and Monica Duffy Toft, editors. Political Demography How Population Changes Are Reshaping International Security and National Politics. Oxford University Press, 2011.

Martin Gonzalez-Eiras and Dirk Niepelt. Population ageing, government budgets, and productivity growth in politico-economic equilibrium. CEPR Discussion Papers 6581, C.E.P.R. Discussion Papers, 2007.

Martin Gonzalez-Eiras and Dirk Niepelt. The future of social security. Journal of Monetary Economics, 55(2):197-218, March 2008. 
Martin Gonzalez-Eiras and Dirk Niepelt. Ageing, government budgets, retirement, and growth. European Economic Review, 56(1):97-115, Jan 2012.

Mark Gradstein and Michael Kaganovich. Aging population and education finance. Journal of Public Economics, 88(12):2469-2485, December 2004.

Ueli Grob and Stefan C. Wolter. Demographic change and public education spending: A conflict between young and old? Education Economics, 15(3):277-292, 2007.

J. Gruber and D. Wise. Social Security and Retirement Around the World. University of Chicago Press, Chicago, 1999.

Peter Hammond. Charity: Altruism or cooperative egoism. In Edmund S. Phelps, editor, Altruism, Morality and Economic Theory, pages 115-31. New York: Russel Sage Foundation, 1975.

Sean Hanley. Explaining the success of pensioners' parties: a qualitative comparative study of 31 polities. In Pieter Vanhuysse and Achim Goerres, editors, Ageing Populations in Post-industrial Democracies: Comparative studies of policies and politics, chapter 2, pages 23-53. Routledge, 2012.

Amy Rehder Harris, William N. Evans, and Robert M. Schwab. Education spending in an aging america. Journal of Public Economics, 81(3):449-472, September 2001.

Robert Holzmann. Global Pension Systems and Their Reform: Worldwide Drivers, Trends, and Challenges. IZA Discussion Papers 6800, Institute for the Study of Labor (IZA), August 2012.

Stefan Homburg. The efficiency of unfunded pension schemes. Journal of institutional and theoretical economics, 146:640-47, 1990.

Stefan Homburg. Interest and growth in an economy with land. The Canadian Journal of Economics / Revue canadienne d'Economique, 24(2):450-459, May 1991. 
Neil Howe and Richard Jackson. The 2003 Aging Vulnerability Index: An Assessment of the Capacity of Twelve Developed Countries to Meet the Aging Challenge. CSIS and Watson Wyatt Worldwide, 2003.

Sheng Cheng Hu. Social security, Majority-Voting equilibrium and dynamic efficiency. International Economic Review, 23(2):269-287, June 1982.

Inigo Iturbe-Ormaetxe and Guadalupe Valera. Social security reform and the support for public education. Journal of Population Economics, 25(2):609-634, January 2012.

Michael. Kaganovich and Volker Meier. Social security systems, human capital, and growth in a small open economy. Journal of Public Economic Theory, 14(4): 573-600, Aug 2012.

Michael Kaganovich and Itzhak Zilcha. Pay-as-you-go or funded social security? a general equilibrium comparison. Journal of Economic Dynamics and Control, 36 (4):455-467, Apr 2012.

Alexander Kemnitz. Demographic structure and the political economy of education subsidies. Public Choice, 101(3-4):235-49, December 1999.

Alexander Kemnitz. Social security, public education, and growth in a representative democracy. Journal of Population Economics, 13(3):443-462, 2000.

Dirk Krueger and Felix Kubler. Pareto-Improving social security reform when financial markets are incomplete!? The American Economic Review, 96(3):737-755, June 2006.

Juan Lacomba and Francisco Lagos. Population aging and legal retirement age. Journal of Population Economics, 19:507-519, 2006.

Juan Lacomba and Francisco Lagos. Political election on legal retirement age. Social Choice and Welfare, 29:1-17, 2007.

Helen F. Ladd and Sheila E. Murray. Intergenerational conflict reconsidered: county demographic structure and the demand for public education. Economics of Education Review, 20(4):343-357, August 2001. 
Francesco Lancia and Alessia Russo. Public Education and Pensions in Democracy: A Political Economy Theory. Memorandum 01/2015, Oslo University, Department of Economics, January 2015.

Marie-Louise Leroux. The political economy of social security under differential longevity and voluntary retirement. Journal of Public Economic Theory, 12(1): 151-170, 2010.

Gilat Levy. The politics of public provision of education. The Quarterly Journal of Economics, 120(4):1507-1534, November 2005.

J.B. Liebman. Redistribution in the current u.s social security system. Working Paper 8625, NBER, 2001.

Peter H. Lindert. The rise of social spending, 1880-1930. Explorations in Economic History, 31(1):1-37, January 1994.

Peter H. Lindert. What limits social spending? Explorations in Economic History, 33(1):1-34, January 1996.

Xavier Mateos-Planas. Demographics and the Politics of Capital Taxation in a Life-Cycle Economy. American Economic Review, 100(1):337-63, March 2010.

V. Meier and M. Werding. Ageing and the welfare state: securing sustainability. Oxford Review of Economic Policy, 26(4):655-673, Dec 2010. ISSN 1460-2121.

Allan H. Meltzer and Scott F. Richard. A rational theory of the size of the government. the Journal of Political Economy, 89(5):914-927, October 1981.

Cynthia Miller. Demographics and spending for public education: a test of interest group influence. Economics of Education Review, 15(2):175-185, Apr 1996.

Juan D. Moreno-Ternero and John E. Roemer. The political economy of health care finance. CORE Discussion Papers 2007031, Université catholique de Louvain, Center for Operations Research and Econometrics (CORE), May 2007. 
Casey B. Mulligan and Xavier Sala-i Martin. Social security in theory and practice (i): Facts and political theories. Economics Working Papers 384, Department of Economics and Business, Universitat Pompeu Fabra, April 1999.

Katsuyuki Naito. Two-sided intergenerational transfer policy and economic development: A politico-economic approach. Journal of Economic Dynamics and Control, 36(9):1340-1348, Sep 2012.

Shinichi Nishiyama and Kent Smetters. Does social security privatization produce efficiency gains? The Quarterly Journal of Economics, 122(4):1677-1719, November 2007.

Robert Nuscheler and Kerstin Roeder. The political economy of long-term care. European Economic Review, 62(C):154-173, 2013.

OECD. Oecd pensions outlook 2014. Technical report, OECD Publishing, 2014.

OECD. Pensions at a glance 2015: Oecd and g20 indicators. Technical report, OECD Publishing, 2015.

Tetsuo Ono. The political economy of environmental taxes with an aging population. Environmental $\&$ Resource Economics, 30(2):165-194, 022005.

Tetsuo Ono. Public education and social security: a political economy approach. Economics of Governance, 16(1):1-25, February 2015.

Oliver Pamp. Political Preferences and the Aging of Populations: Political-Economy Explanations of Pension Reform. Springer VS, 2015.

Pierre Pestieau and Grégory Ponthière. The Long Term Care Insurance Puzzle. In Joan Costa-Font Christophe Courbage, editor, Financing Long Term Care in Europe: Institutions. Markets and Models. Palgrave Macmillan, December 2011.

Tomas J. Philipson and Gary S. Becker. Old-age longevity and mortality-contingent claims. Journal of Political Economy, 106(3):551-573, June 1998.

Christopher Pierson. Beyond the welfare state? : the new political economy of welfare. Penn State University Press, University Park, Pennsylvania, 2007. 
Charles R. Plott. A notion of equilibrium and its possibility under majority rule. American Economic Review, 57:787-806, 1967.

James M. Poterba. Demographic structure and the political economy of public education. Journal of Policy Analysis and Management, 16(1):48-66, 1997.

Panu Poutvaara. On the political economy of social security and public education. Journal of Population Economics, 19(2):345-365, June 2006.

Paola Profeta. Aging and retirement: Evidence across countries. International Tax and Public Finance, 9(6):651-672, November 2002.

Antonio Rangel. Social security reform: Efficiency gains or intergenerational redistribution. mimeo, Harvard university, 1997.

Antonio Rangel. Forward and backward intergenerational goods: Why is social security good for the environment? American Economic Review, 93(3):813-834, Jun 2003.

Assaf Razin, Efraim Sadka, and Phillip Swagel. The aging population and the size of the welfare state. Journal of Political Economy, 110(4):900-918, August 2002.

John E. Roemer. Political competition: Theory and applications. Harvard University Press, Cambridge, 2001.

Paul A. Samuelson. An exact Consumption-Loan model of interest with or without the social contrivance of money. Journal of Political Economy, 66(6):467-482, December 1958.

Ismael Sanz and Francisco J. Velazquez. The role of ageing in the growth of government and social welfare spending in the oecd. European Journal of Political Economy, 23(4):917-931, December 2007.

Cameron A. Shelton. The aging population and the size of the welfare state: Is there a puzzle? Journal of Public Economics, 92(3-4):647-651, April 2008.

Kenneth Shepsle. Institutional arrangements and equilibrium in multidimensional voting models. American Journal of Political Science, 23(1):27-59, 1979. 
Eytan Sheshinski. A model of social security and retirement decisions. Journal of Public Economics, 10(3):337-360, December 1978.

András Simonovits. Can population ageing imply a smaller welfare state? European Journal of Political Economy, 23(2):534 - 541, 2007.

Hans-Werner Sinn and Silke Uebelmesser. Pensions and the path to gerontocracy in Germany. European Journal of Political Economy, 19(1):153-158, March 2003.

Kriss Sjoblom. Voting for social security. Public Choice, 45:225-240, 1985.

Jorge Soares. A dynamic general equilibrium analysis of the political economy of public education. Journal of Population Economics, 19(2):367-389, Jun 2006.

Rune J. Sorensen. Does aging affect preferences for welfare spending? a study of peoples' spending preferences in 22 countries, 1985 2006. European Journal of Political Economy, 29(C):259-271, 2013.

Guido Tabellini. A positive theory of social security. The Scandinavian Journal of Economics, 102(3):523-545, 2000.

Markus Tepe and Pieter Vanhuysse. Accelerating smaller cutbacks to delay larger ones? the politics of timing and alarm bells in oecd pension generosity retrenchment. In Pieter Vanhuysse and Achim Goerres, editors, Ageing Populations in Post-industrial Democracies: Comparative studies of policies and politics, chapter 6, pages 127-144. Routledge, 2012.

United Nations. World population prospects: The 2015 revision, key findings and advance tables. Technical report, U.N. Department of Economic and Social Affairs, Population Division, 2015.

U.S. Social Security Administration. Social security programs throughout the world: The americas, 2015. Technical report, Social Security Administration, 2016.

Salvador Valdés-Prieto, editor. The Economics of Pensions. Number 9780521666121 in Cambridge Books. Cambridge University Press, 1999. 
Pieter Vanhuysse and Achim Goerres, editors. Ageing Populations in Post-industrial Democracies: Comparative studies of policies and politics. Routledge, 2012.

World Bank. The world bank pension conceptual framework. Technical report, World Bank pension reform primer series, 2008. 


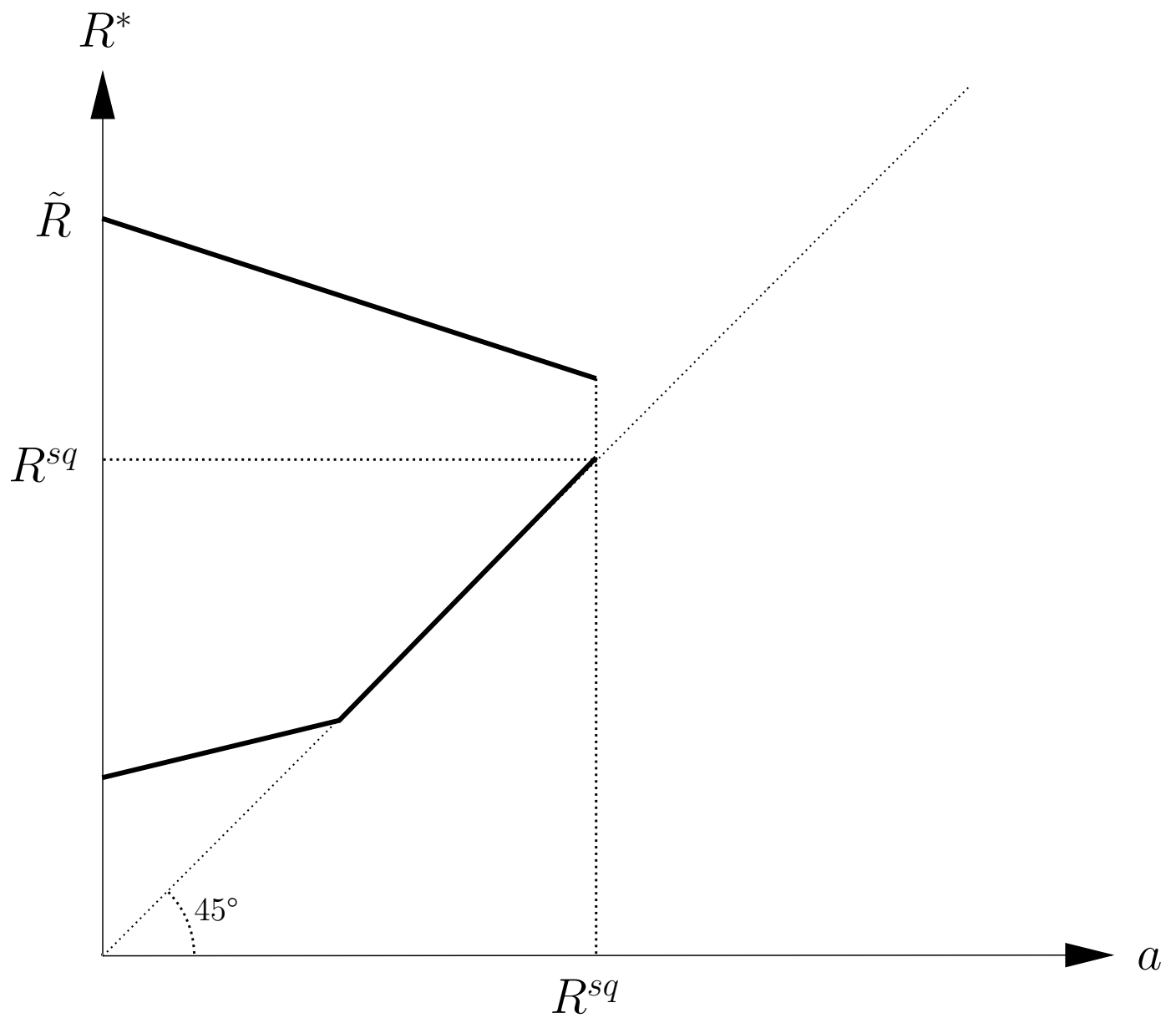

Figure 1: Optimal retirement ages of the workers 